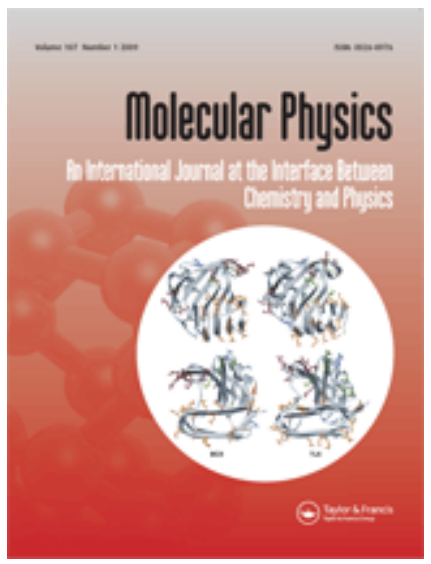

\title{
(SI) Photodissociation of vibrationally excited OH/OD
} radicals

\begin{tabular}{|r|l|}
\hline Journal: & Molecular Physics \\
\hline Manuscript ID: & TMPH-2007-0304.R1 \\
\hline Manuscript Type: & Full Paper \\
\hline Date Submitted by the \\
Author: & 06-Dec-2007 \\
\hline Complete List of Authors: & $\begin{array}{l}\text { Parker, David; IMM, Molecular and Laser Physics } \\
\text { Groenenboom, Gerrit; IMM, Theoretical Chemistry }\end{array}$ \\
\hline Keywords: & $\begin{array}{l}\text { hydroxyl radical, photodissociation, state selection, atom } \\
\text { polarization, sudden limit model }\end{array}$ \\
\hline
\end{tabular}

\section{S ScholaroNE \\ Manuscript Central}




\section{Photodissociation of vibrationally excited $\mathrm{OH} / \mathrm{OD}$ radicals}

Dragana Č. Radenović, André J. A. van Roij, Shiou-Min Wu, J. J. ter Meulen, and David H. Parker ${ }^{1}$

Molecular and Laser Physics, IMM, Radboud University Nijmegen, Toernooiveld 1, 6525ED, Nijmegen, The Netherlands

Mark P. J. van der Loo, Liesbeth M. C. Janssen and Gerrit C. Groenenboom,

Theoretical Chemistry, IMM, Radboud University Nijmegen, Toernooiveld 1, 6525ED, Nijmegen, The Netherlands

Keywords:

hydroxyl radical, photodissociation, state selection, atom polarization, sudden limit model.

\footnotetext{
${ }^{1}$ Corresponding author: phone +31 24 3652423; fax +31 24 3653311; email parker@science.ru.nl.
} 


\begin{abstract}
This paper describes a joint experimental and theoretical study of the photodissociation of vibrationally excited hydroxyl radicals. $\mathrm{OH}$ and $\mathrm{OD}$ radicals produced in a pulsed electric discharge supersonic beam are state-selected and focused by a hexapole and then photo-dissociated by a single laser tuned to various $\mathrm{H} / \mathrm{D}$ or $\mathrm{O}$ atom $(2+1)$ resonance enhanced multiphoton ionization (REMPI) wavelengths between $243 \mathrm{~nm}$ and $200 \mathrm{~nm}$. The angle velocity distributions of the resulting $\mathrm{O}^{+}$and $\mathrm{D}^{+}$photofragment ions were recorded using velocity map imaging. Photodissociation to the $\mathrm{O}\left({ }^{3} \mathrm{P}_{\mathrm{J}}\right)+\mathrm{H}\left({ }^{2} \mathrm{~S}\right)$ limit is shown to take place by one-photon excitation to the repulsive $1^{2} \Sigma^{-}$state. The experimental data shows that vibrationally excited $\mathrm{OH} / \mathrm{OD}$ which are formed in the discharge are dissociated, and a vibrational temperature of $\sim 2000 \mathrm{~K}$ was estimated for the beam source. An analysis in the high-energy recoil sudden limit is used to predict the $O\left({ }^{3} \mathrm{P}_{J}\right)$ fine structure branching ratios and alignment information in the molecular and laboratory velocity frame of the imaging experiment. The measured and predicted fine structure branching ratios and alignment parameters agree well at all dissociation wavelengths, supporting the model for photodissociation in the sudden limit regime. Several aspects of the experiment such as $\mathrm{OH}$ pre-alignment and orientation, ionrecoil, and Doppler-free imaging are discussed.
\end{abstract}




\section{INTRODUCTION}

Due to its central role in the photochemistry of the Earth's atmosphere, in combustion processes and in the interstellar medium, the spectra and photodynamics of the highly reactive hydroxyl radical $(\mathrm{OH})$ has been the subject of numerous theoretical and experimental investigations. A wealth of detailed theoretical predictions for the photodissociation dynamics of $\mathrm{OH}$ is available from studies using high-quality ab-initio calculations of the $\mathrm{OH}$ electronic structure. Despite its importance, experimental studies of $\mathrm{OH}$ photodissociation under collision-free conditions have only recently been reported ${ }^{1,2}$.

Examination of the $\mathrm{OH}$ potential energy curves, Figure 1, for the optically accessible excited electronic states reveals why laboratory studies of $\mathrm{OH}$ photodissociation are so challenging. Given the $\mathrm{O}-\mathrm{H}$ bond dissociation energy, $\mathrm{D}_{0}$, of $4.37 \mathrm{eV}^{3}$, photodissociation of $\mathrm{OH}$ can in principle occur at wavelengths shorter than $284 \mathrm{~nm}$. Transitions to vibrational levels $\mathrm{v}^{\prime} \geq 1$ of the $\mathrm{A}^{2} \Sigma^{+}$state from the $x^{2} \Pi$ ground electronic state, which lie in the ultraviolet (UV) region of the spectrum and are used for laser induced fluorescence detection of $\mathrm{OH}$, lead to predissociation, producing $\mathrm{O}\left({ }^{3} \mathrm{P}\right)+\mathrm{H}\left({ }^{2} \mathrm{~S}\right)$ atoms. Van Dishoeck and Dalgarno ${ }^{4}$ have shown that the total dissociation yield for this $A^{2} \Sigma^{+} \leftarrow X^{2} \Pi$ transition is much smaller $\left(\sim 10^{-5}\right)$ than photodissociation from the higher energy electronic states, thus the $A^{2} \Sigma^{+} \leftarrow X^{2} \Pi$ channel (when starting from the lowest vibrational levels of the $X$ state) is in most circumstances of no importance in the total photodissociation process.

All of the remaining allowed electronic transitions, to the repulsive ${ }^{2} \Sigma^{-},{ }^{2} \Delta$, and ${ }^{2} \Pi$ upper states that dominate photodissociation of $\mathrm{OH}$, lie in the vacuum ultraviolet (VUV) spectral region where intense laser sources are not readily available. VUV photodissociation is the main destruction process of $\mathrm{OH}$ in diffuse clouds in the interstellar medium, where VUV radiation is intens $\mathrm{e}^{5,6}$. Besides the VUV difficulty, most sources of $\mathrm{OH}$ radicals also co-produce large amounts of $\mathrm{O}\left({ }^{3} \mathrm{P}_{\mathrm{J}}\right)$ and $\mathrm{H}\left({ }^{2} \mathrm{~S}\right)$ atoms, which can overwhelm the detection of photo-product signals. 
Formatted: Superscript

under collision-free conditions, with state-specific detection of the $\mathrm{D}$ and $\mathrm{O}$ atom products $\mathrm{s}_{-}^{\frac{1}{4}} \mathrm{Our} \mathrm{OH}$ beam source $\mathrm{T}_{\mathbf{Y}}^{\mathrm{7}}$ produces small amounts of vibrationally excited $\mathrm{OH}$, and the internal vibrational energy, $E_{v i b}$, allows photodissociation by UV instead of VUV radiation, where $h v_{U V}=h v_{v u v}-E_{v i b}$. Due to the very low amounts of the higher vibrational states in the molecular beam, it was necessary to perform a one-laser experiment, where a single laser beam is used for both photodissociation of $\mathrm{OH}$ and detection of the $\mathrm{O}$ or $\mathrm{H}$ photo-products. This provides higher sensitivity but less flexibility than a two-laser experiment. With this approach, we have carried out a series of studies of direct photodissociation of $\mathrm{OH}$ and $\mathrm{OD} \underset{\Delta \mathrm{Y}}{\frac{1}{2}}$ as well as the isovalent molecules $\mathrm{SH}$ and $\mathrm{SD}{ }^{9}$. A two-laser dissociation-probe scheme (exciting the most populated $x^{2} \Pi\left(v^{\prime \prime}=0\right)$ level) is also being used in our laboratory to study predissociation of the $A^{2} \Sigma^{+}$state of all four molecules. Using the high resolution $\mathrm{H}$ atom Rydberg tagging method, Zhang and co-workers have reported $A^{2} \Sigma^{+}$state predissociation of $\mathrm{OH} / \mathrm{OD}_{\mathrm{Av}}^{2}$ and direct UV photo-dissociation of $\mathrm{SH} / \mathrm{SD}^{10}$ and the results of these two different but complementary experimental approaches are compared in this paper.

Our previous Communication $\frac{1}{2}$ described photodissociation of OD radicals using velocity map imaging to probe the speed and angular distribution of the $\mathrm{D}\left({ }^{2} \mathrm{~S}\right)$ products formed by photodissociation of OD at $243 \mathrm{~nm}$, and the $\mathrm{O}\left({ }^{3} \mathrm{P}_{2}\right)$ atom products of $\mathrm{OH} / \mathrm{OD}$ photodissociation at $226 \mathrm{~nm}$. This paper describes extended studies of state-selected $D\left(n=1,{ }^{2} S\right)$ atom detection from OD at $243 \mathrm{~nm}$ as well as at $205 \mathrm{~nm}$, along with studies of the different J = 2, 1, 0 fine structure states of the $\mathrm{O}\left({ }^{3} \mathrm{P}_{\mathrm{J}}\right)$ atoms following photodissociation of $\mathrm{OD}$ and $\mathrm{OH}$ at $226 \mathrm{~nm}$ and $200 \mathrm{~nm}$. Doppler-free imaging of OD photodissociation with $D$ atom detection at $243 \mathrm{~nm}$ and ion-recoil effects in OH/OD photodissociation imaging is also described. We show from experiment and first principle 


\section{PHOTODISSOCIATION OF OH}

$A b$ initio potential energy curves for the ground and lower electronically excited states of $\mathrm{OH}(X$ $\left.{ }^{2} \Pi, A^{2} \Sigma^{+}, 1^{2} \Sigma^{-}, 1^{4} \Sigma^{-}, 1^{4} \Pi, 1^{2} \Delta, 2^{2} \Pi\right)$ calculated by van der Loo and Groenenboom ${ }^{11}$ are presented in Figure 1. In the $\mathrm{OH} X^{2} \Pi$ ground state (Hund's case b) the ${ }^{2} \Pi_{3 / 2}$ spin-orbit component is $123 \mathrm{~cm}^{-1}$ lower in energy than ${ }^{2} \Pi_{1 / 2} \cdot{ }^{12}$ The $\mathrm{OH} X^{2} \Pi$ ground state and the $1^{2} \Sigma^{-}, 1^{4} \Pi$, and $1^{4} \Sigma^{-}$repulsive states correlate adiabatically with ground state product atoms $\mathrm{O}\left({ }^{3} \mathrm{P}_{\mathrm{J}}\right)+\mathrm{H}\left(\mathrm{n}=1,{ }^{2} \mathrm{~S}\right)$, while the first excited bound state $A^{2} \Sigma^{+}$, and the repulsive states $1^{2} \Delta$ and $2^{2} \Pi$ correlate with the second dissociation limit $\left[\mathrm{O}\left({ }^{1} \mathrm{D}_{2}\right)+\mathrm{H}\left(\mathrm{n}=1,{ }^{2} \mathrm{~S}\right)\right] . \quad$ Van Dishoeck and Dalgarno $0_{\Delta}^{4}$ showed that absorption to the repulsive $1^{2} \Sigma^{-},{ }^{2} \Delta$, and $^{2} \Pi$ states corresponds to strong, broad bands in the VUV region of the spectrum peaking at 7.81 , 9.79, and $11.25 \mathrm{eV}$, respectively. They pointed out that direct photodissociation via the $1^{2} \Sigma^{-}$state (which is repulsive at all distances) is the major destruction mode for $\mathrm{OH}$ in diffuse interstellar clouds and in comets $\mathrm{s}^{6}$ Yarkony $^{13}$, and others ${ }^{14}$, have predicted the final product quantum state distributions for direct dissociation and pre-dissociation of $\mathrm{OH}$, which in general follow the expectations for a 'sudden limit' diabatic process. Lee ${ }^{15}$, however, predicted large deviations from the sudden limit model due to interference effects from simultaneous absorption to the repulsive wall of the $A^{2} \Sigma^{+}$state and the $1^{2} \Sigma^{-}$repulsive state. Most recently, van der Loo and Groenenboom

calculations that our images are due to one-photon dissociation to the first dissociation limit of was clearly observed and characterized in the UV photodissociation of the SH and SD molecules, as reported previously $y_{-1}^{9}$ The $\mathrm{O}^{1}\left({ }^{1} \mathrm{D}\right)$ channel from $\mathrm{OH}$ is the subject of on-going investigation in our 
As the $\mathrm{OH} 1^{2} \Sigma^{-}$state correlates adiabatically with the $\mathrm{O}\left({ }^{3} \mathrm{P}_{0}\right)+\mathrm{H}\left({ }^{2} \mathrm{~S}\right)$ limit $\frac{15}{15}$ at the threshold for photodissociation these are the only products expected. However, as seen in Figure 1, FranckCondon overlap limits absorption from the lower vibrational states of the $\mathrm{OH} X$ state only to excited electronic states lying well above the first dissociation limit. OH photodissociation is most likely a diabatic process due to this large excess energy, and due to the small mass and thus high velocity of the recoiling $\mathrm{H}$ atom. In the diabatic picture, the electronic Hamiltonian (without spin-orbit coupling) is diagonalized and spin-orbit interactions can cause coupling of the diabatic curves along the dissociation coordinate. If the excess energy is much larger than the spin-orbit coupling (among the $1^{2} \Sigma, 1^{4} \Pi$, and $1^{4} \Sigma$ repulsive states) there is insufficient time for the electronic and spin angular momentum to recouple at the large internuclear distance. Dissociation is then in the high-energy recoil or 'sudden' limit and takes place essentially on the optically prepared diabatic state. In this limit, the projection of the molecular wave function of the initial diabatic state onto the atomic basis 


\section{SUDDEN LIMIT ANALYSIS OF OH PHOTODISSOCIATION}

\section{Potential energy curves for the $X^{2} \Pi$ and $1^{2} \Sigma$ states, reported by van der Loo and}

Groenenboom $\frac{11}{1}$ are used in this section to predict the wavelength dependent photodissociation cross sections for $\mathrm{OH} X\left(\mathrm{v}^{\prime \prime}=0-5\right)$, and their contribution in the final $\mathrm{O}\left({ }^{3} \mathrm{P}_{\mathrm{J}}\right)$ product distributions including polarization information (as prescribed for sudden-limit dissociation) in the molecular body-fixed $(J, \omega)$ and laboratory $\left(J, M_{J}\right)$ frame. This analysis is used later in the article for interpretation of and comparison with the experimental data. A sudden limit analysis in the molecular body-fixed $(J, \omega)$ and laboratory $\left(J, M_{J}\right)$ frame for photodissociation via the repulsive wall of the $A^{2} \Sigma^{+}$state to the second dissociation limit was carried out in reference 9 for SH and SD. This analysis is identical for $\mathrm{OH}$ and $\mathrm{OD}$ and is not repeated here.

\subsection{Photodissociation cross sections}


$A b$ initio calculations of the $\mathrm{OH} / \mathrm{OD}$ ground- and excited state potential energy surfaces and internuclear distance-dependent dipole transition moments are described in reference 11. Briefly, the potential energy curves and dipole transition moments are computed with MOLPRO ${ }^{17}$ at the internally contracted multireference configuration interaction level ${ }^{18,19}$, with single and double excitations. Orbitals are obtained from complete active space self consistent field calculations $\mathrm{s}^{20,21}$, using an aug-cc-pV6Z one-electron basis set. We use the sinc-DVR method ${ }^{22,23}$ to compute the nuclear vibrational wave functions and renormalized Numerov propagation to compute the nuclear dissociative wave functions.

The $X^{2} \Pi\left(v^{\prime \prime}\right)$ vibrational quantum state dependent photodissociation cross section (see Figure 1) $\sigma$ in $\mathrm{cm}^{2}$ is given by:

$$
\sigma(\omega)=\frac{4 \pi^{2} \alpha \hbar \omega}{3 e^{2}}\left|\left\langle 1^{2} \Sigma^{-}, E\left|\mu_{\mathrm{x}}\right| X^{2} \Pi_{\mathrm{x}}(\mathrm{v})\right\rangle\right|^{2}
$$

where $\alpha$ is the fine-structure constant, $e$ the elementary charge, $\omega$ the frequency of the absorbed photon, $E$ the kinetic energy release, $\mu_{x}$ the $x$-component of the electronic dipole operator, and $v$ the vibrational level of the ground state.

Wavelength dependent photodissociation cross sections in $\mathrm{cm}^{2}$ are plotted in the left side Figure 1 for photodissociation beginning from the $\mathrm{OH} X\left({ }^{2} \Pi\right) v^{\prime \prime}=0,2$, and 3 vibrational states. For the $\mathrm{OH} X$ $\left(v^{\prime \prime}=0\right)$ state, our maximum value of $3.15 \times 10^{-18} \mathrm{~cm}^{2}$ for the photodissociation cross section (at $\sim 155$ $\mathrm{nm}$ ) agrees well with the value of $3.32 \times 10^{-18} \mathrm{~cm}^{2}$ calculated by van Dishoeck and Dalgarno 4 absorption cross section of $\sim 2 \times 10^{-18} \mathrm{~cm}^{2}$ at $155 \mathrm{~nm}$ was measured by Lee and $\mathrm{Nee}^{24}$ using synchrotron radiation. For our UV photodissociation wavelengths around $200 \mathrm{~nm}$, the $\mathrm{v}^{\prime \prime}=2$ and $\mathrm{v}^{\prime \prime}=3$ states show local maxima while essentially no photodissociation occurs when starting from $v^{\prime \prime}=0$.

\subsection{Molecular and Lab frame polarization of the $\mathrm{O}\left({ }^{3} \mathrm{P}_{J}\right)$ fragment}


The $\mathrm{O}$ atom angular distribution can be written as

$I(\theta) \propto 1+\beta P_{2}(\cos \theta)$, polarization vector and the recoil velocity. In the sudden recoil limit $\beta=-1$ for the perpendicular transition $1^{2} \Sigma^{-} \leftarrow X^{2} \Pi$. The oxygen ion image may deviate from this distribution if the $O\left({ }^{3} \mathrm{P}_{J}\right)$ atoms are polarized. The ion image angular distribution can be expanded as

$$
I_{J}^{\text {ion }}(\theta)=p_{J} \sum_{k=0.2,4} c_{k}(J) P_{k}(c c
$$

where are the fine-structure branching ratios. Expressions for the expansion coefficients

$$
\text { in the sudden recoil limit are given by }{ }^{25}
$$

$$
\mathrm{c}_{0}(\mathrm{~J})=\quad 1+\frac{1}{5} \beta \bar{\rho}_{0}^{(2)}(D) I_{1}
$$

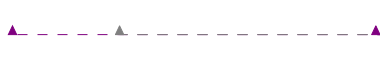$$
\mathrm{c}_{2}(\mathrm{~J})=\beta+\left(1+\frac{2}{7} \beta\right) \bar{\rho}_{0}^{(2)}(\mathrm{D}) l,
$$$$
\mathrm{c}_{4}(\mathrm{~J})=\beta \quad \bar{\rho}_{0}^{(2)}(J) l
$$

where $\bar{\rho}_{0}^{(c)}=\rho_{0}^{(2)}(J) / \rho_{0}^{(\mathrm{Cc}}$. The rank $k$ irreducible components of the density matrix

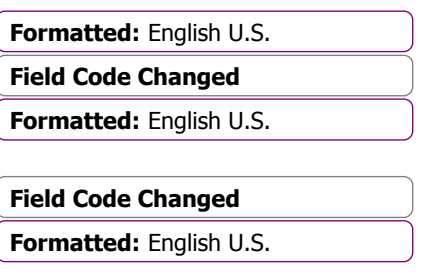

(4)

Formatted: English U.S. 
$\rho_{0}^{(k)}$ are related to the populations $\mathrm{p}_{\mathrm{j} \omega}$ of the molecule-fixed fine-structure states of the oxygen

fragment, , through

$$
\rho_{0}^{(k)} \zeta \quad \Sigma_{\omega=-J}^{J}(-1)^{I-\omega}\left(J, \omega_{i} J,-\omega \mid k 0\right.
$$

where $\quad\langle, \omega, l,-\omega|$ are Clebsch-Gordan coefficients. The relative absorption intensities $I_{2}(J)$ for

the $(2+1)$ REMPI oxygen detection scheme as defined by Mo et al. ${ }^{26}$ are $I_{2}(1)=1 / \sqrt{ } 2$ and $I_{2}(2)=$

(ref 25). In the above equations we already substituted $\mathrm{I}_{4}(2)=0$.

In the sudden recoil limit the populations $J \omega$ are computed by expanding the $1^{2} \Sigma^{-}$molecular

basis $\quad \mid \Lambda=0, \mathrm{~S}=1 / \AA$ excited state in the product atomic basis $\mathrm{S}_{\mathrm{H}}=1 / 2, \sigma_{\mathrm{H}}|\mathrm{J} \omega\rangle^{25,27}$. Here $\Sigma$

is the projection of the molecular spin onto the interatomic axis. Since the $\mathrm{H}$ atom is in an S-state,

we only require the $\mathrm{H}$-atom spin wave function $\quad \mathrm{S}_{\mathrm{H}} \sigma_{\mathrm{H}}$ ) and the orbital part of the $O\left({ }^{3} \mathrm{P}\right)$ oxygen 
atom is given by $L \wedge$, with $L=1$. The spin part of the molecular wave function can be written as the

$$
S \Sigma\rangle=\sum_{\sigma_{H} \sigma_{0}}\left|S_{H} \sigma_{H}\right\rangle \mid S_{O} \quad\left\langle S_{H} \sigma_{H} S_{O} \sigma_{O}\right|
$$

The uncoupled O-atom wave function may be expanded in fine-structure states through

$$
\left.|L \Lambda\rangle\left|S_{0} \sigma_{0}\right\rangle=\Sigma_{j=0}^{2} \Sigma_{\omega=-J}^{J} \mid J \omega\right)\left(L \Lambda S_{0} \sigma_{0}\right.
$$

Combining the last two equations gives

$$
|\Lambda S \Sigma\rangle=\sum J \omega \sigma_{H} \sigma_{O}\left|S_{H} \sigma_{H}\right\rangle|J \omega\rangle\left\langle S_{H} \sigma_{H} S_{O} \sigma_{O} \mid S \Sigma\right\rangle\left\langle L \Lambda S_{0} \sigma_{0} \mid J \omega\right\rangle
$$

and we find for the molecular state $1^{2} \Sigma^{-}$, with $\Lambda=0$, and $S=1 / 2$ and $|\Omega|=|\Sigma|=1 / 2$, in the sudden recoil limit

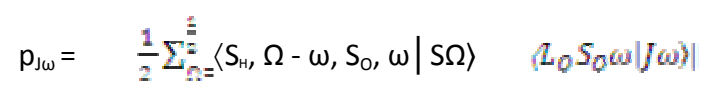


The fine-structure branching ratios for the oxygen atoms are given by $p_{\jmath}=\Sigma_{\Delta}$. The

branching ratios for the ions, i.e., taking into account the polarization effects are given by

$$
=\frac{z_{j} e_{1}}{\Sigma_{l} p_{j}}
$$

The fine-structure populations and the Legendre moments of the normalized ion images, $\beta_{\mathrm{J}}=$ $\mathrm{c}_{2}(\mathrm{~J}) / \mathrm{c}_{0}(\mathrm{~J})$ and $\gamma_{\mathrm{J}}=\mathrm{c}_{4}(\mathrm{~J}) / \mathrm{c}_{0}(\mathrm{~J})$ are given in Table 1. There are, for example, no projections possible of the ${ }^{2} \Sigma^{-}$electronic state $(\Omega=1 / 2)$ onto a final state configuration of $H\left({ }^{2} S_{1 / 2}\right)$ and $O\left({ }^{3} P_{2}\right)(\Omega=5 / 2,3 / 2)$. Inspection of Table 1 shows that the $O\left({ }^{3} \mathrm{P}_{\mathrm{J}}=2: 1: 0\right)$ fine-structure branching ratios are the same as the statistical 5:3:1 pattern, but the distributions $\mathrm{p}_{\mathrm{J} \omega}$ for a given J value are far from statistical. The branching ratios $r_{\mathrm{J}}$, that are obtained from integrating the angular distributions and that take into account the polarization effects, deviate slightly from the atomic branching ratios $p_{\text {. }}$. Note that the $\mathrm{J}=0 \mathrm{O}\left({ }^{3} \mathrm{P}_{0}\right)$ product atom shows the expected $\beta=-1$ for a $\Sigma \leftarrow \Pi$ excitation, while $\mathrm{J}=1$ and 2 have $\beta<-1$ and significant (negative) $\gamma$ values.

\section{EXPERIMENTAL METHOD}


1

2

3

4

5

6

7

8

9

10

11
Our velocity map imaging apparatus has been described in detail elsewhere $\frac{1}{1}, \frac{16}{2}$ thus only a summary of the experimental details concerning the molecular beam and hexapole state selector will be given here. Two differentially pumped vacuum chambers are used: one chamber for the production of $\mathrm{OH} / \mathrm{OD}$ molecules and the other chamber for the state selection of $\mathrm{OH} / \mathrm{OD}$ photodissociation, and detection of one of the fragments from OH/OD. The source chamber is pumped by a diffusion pump and the detection chamber is differentially pumped by a turbo pump with additional pumping by a liquid $\mathrm{N}_{2}$-cold trap. The $\mathrm{OH} / \mathrm{OD}$ beam source was produced by a mixture of $\mathrm{H}_{2} \mathrm{O} / \mathrm{D}_{2} \mathrm{O}$ molecules seeded in $\mathrm{Ar}$ as the carrier gas. The mixture is prepared by bubbling Argon at a backing pressure of 1.5 bar through liquid water at room temperature (vapor pressure of $24 \mathrm{mbar}$ ). For the expansion a Jordan pulsed valve with a $0.4 \mathrm{~mm}$ diameter nozzle is used, which is mounted along the direction of the time of flight tube. The OH/OD radicals are produced by dissociation of $\mathrm{H}_{2} \mathrm{O} / \mathrm{D}_{2} \mathrm{O}$ at the beginning of the expansion by an electrical discharge between a stainless steel ring ( $4 \mathrm{~mm}$ diameter, $0.5 \mathrm{~mm}$ thick) and the grounded valve body ${ }^{7}$. The ring, which is located on-axis $2.5 \mathrm{~mm}$ from the nozzle, is pulsed ( $20 \mu \mathrm{sec}, 2 \mathrm{kV}$ ) to negative high voltage during the $\sim 60 \mu$ sec expansion. between the valve and the collision zone is $220 \mathrm{~mm}$. The enlargement of the distance between the

$$
\sim 60 \mu \text { sec expansion. }
$$

\begin{abstract}
After their production, the electrically neutral $\mathrm{OH} / \mathrm{OD}$ molecules cool down to the ground rotational level of each vibrational state in the supersonic expansion and pass through a $1 \mathrm{~mm}$ diameter skimmer which separates the source and detection chambers. The skimmer is positioned $15 \mathrm{~mm}$ from the nozzle. The cold molecular beam enters a $120 \mathrm{~mm}$ long hexapole state selector 50 $\mathrm{mm}$ downstream of the nozzle, which focuses $\mathrm{OH} / \mathrm{OD}$ in the $\Omega=3 / 2, \mathrm{~J}=3 / 2,\left|\mathrm{M}_{\mathrm{J}}\right|=3 / 2,1 / 2$ states in the upper $\Lambda$-doublet of $f$-symmetry ${ }^{28}$ to the laser interaction region between the repeller plate and the extractor plate of the electrostatic lens. The hexapole is constructed with $3 \mathrm{~mm}$ cylindrical rods and has an inner diameter of $6 \mathrm{~mm}$. The distance from the entrance of the hexapole to the valve and the distance from the exit of the hexapole to the collision center is $50 \mathrm{~mm}$. The total distance
\end{abstract}

(1)


source and photodissociation area by the insertion of the state selector decreases the contributions from all other species in the discharge beam, while the hexapole increases the concentration of the state-selected component by a factor of $\sim 8$ at the crossing point with the photodissociation laser.

Using both laser induced fluorescence (LIF) and resonance enhanced multiphoton ionization (REMPI) detection techniques ${ }^{29,30}$ the only species in the beam that was found to focus with the hexapole was $\mathrm{OH} / \mathrm{OD}$. A corresponding increase in signal for the photodissociation processes with the hexapole 'on' is thus direct proof that the photodissociation signal arises from OH/OD. The UV laser beam propagates perpendicular to the molecular beam and is focused with a $200 \mathrm{~mm}$ focal length lens, and has its electric field polarization direction lying parallel to the detector face. In our experiments only one laser is used, both for dissociation of the $\mathrm{OH} / \mathrm{OD}$ and detection of one of the fragments $\mathrm{O}\left({ }^{3} \mathrm{P}_{2,1,0}\right)$ from $\mathrm{OH}, \mathrm{O}\left({ }^{3} \mathrm{P}_{2,1,0}\right)$ from $\mathrm{OD}$ or $\mathrm{D}\left({ }^{2} \mathrm{~S}\right)$ from $\mathrm{OD}$. There was too much apparatus background to detect $\mathrm{H}$ from $\mathrm{OH}$. The laser wavelength is chosen for two-photon resonant threephoton ionization [(2+1) REMPI] of either the $\mathrm{O}\left({ }^{3} \mathrm{P}_{2,1,0}\right)$ atom products at $\sim 226 \mathrm{~nm}$ and $\sim 200 \mathrm{~nm}^{31}$ or the $D\left({ }^{2} S\right)$ atom products at $\sim 243 \mathrm{~nm}$ and $\sim 205 \mathrm{~nm}$. We find that the relative sensitivity for all three $\mathrm{O}\left({ }^{3} \mathrm{P}_{\mathrm{J}}\right)$ states at $\sim 200 \mathrm{~nm}$ is similar and that the overall sensitivity is a factor of $\sim 7$ lower than at $\sim 226$ $\mathrm{nm}$ for similar experimental conditions.

UV laser light of $\sim 2 \mathrm{~mJ} /$ pulse was generated by frequency doubling the output of a dye laser (Continuum TDL60) for 226nm (Coumarin $47 \mathrm{dye}$ ) and $\sim 243 \mathrm{~nm}$ (Coumarin $102 \mathrm{dye}$ ). In the 200$205 \mathrm{~nm}$ region $\sim 1 \mathrm{~mJ} /$ pulse was generated by frequency tripling the output of a dye laser (Spectra Physics Quanta Ray PDL-2) operating with a mixture of Sulforhodamine B and Rhodamine 640. Ions created in the laser-molecular beam intersection area are extracted and rapidly accelerated into the time-of-flight region by an electrostatic velocity mapping lens consisting of a $100 \mathrm{~mm}$ diameter repeller, extractor, and ground plates separated by $15 \mathrm{~mm}$. The repeller electrode has a $4 \mathrm{~mm}$ center opening and the other two lenses have openings of $20 \mathrm{~mm}$. At the end of the TOF tube the ions strike a position sensitive detector, which consists of two microchannel plates (MCP) followed by a 
1

3

P-20 phosphor screen. Mass selectivity was achieved by pulsing on the gain of the detector as the $\mathrm{D}^{+}$ or $\mathrm{O}^{+}$ions arrive. The 2-D images on the phosphor screen are recorded with a CCD camera and stored in a PC where further data analysis is performed.

\section{EXPERIMENTAL RESULTS AND ANALYSIS}

\subsection{General description of the images}

A set of raw photofragment images of $\mathrm{O}^{3}\left(\mathrm{P}_{\mathrm{J}}\right)$ photofragments from the photo-dissociation of $\mathrm{OH}$ and $O D$, and $D\left({ }^{2} S\right)$ photofragments from the photodissociation of $O D$ are shown in Figure 2. These images are 2D projections of the 3D velocity distributions with the polarization vector of the photodissociation laser beam maintained parallel to the detector face and thus along the vertical axis of the figure. All of the images show a strong spot in the middle of the image which corresponds to $O\left({ }^{3} \mathrm{P}_{\mathrm{J}}\right)$ or $\mathrm{D}\left({ }^{2} \mathrm{~S}\right)$ atoms formed in the discharge and cooled in the expansion.

State-selective detection of $\mathrm{O}\left(2 \mathrm{p}^{4}{ }^{3} \mathrm{P}_{\mathrm{J}}\right)$ is achieved either by two-photon resonant, one-photon ionization $\left((2+1)\right.$ REMPI) through the $\mathrm{O}\left(2 \mathrm{p}^{3} 3 \mathrm{p}^{1},{ }^{3} \mathrm{P}_{\mathrm{J}}\right)$ states using the vacuum wavelengths of 225.654 , 226.059 and $226.233 \mathrm{~nm}$ for $\mathrm{J}=2,1,0$, respectively or by $(2+1)$ REMPI through the $O\left(2 \mathrm{p}^{3} 4 \mathrm{p}^{1},{ }^{3} \mathrm{P}_{\mathrm{J}}\right)$ states using the vacuum wavelengths of $200.640,200.959$ and $201.097 \mathrm{~nm}$ for $\mathrm{J}=2,1,0$, respectively. State-selective detection of $D\left(1 s^{2} S\right)$ is achieved either by $(2+1)$ REMPI through the $D\left(2 s^{2} S\right)$ state using the vacuum wavelengths $243.09 \mathrm{~nm}$ or by $(2+1)$ REMPI through the $D\left(3 \mathrm{~s}^{2} \mathrm{~S}\right)$ states using $205.07 \mathrm{~nm}$. The images shown in Figure 2 are calibrated using $\mathrm{O}\left({ }^{3} \mathrm{P}_{2}\right)$ from the photodissociation of $\mathrm{O}_{2}$ at $\sim 226 \mathrm{~nm}$ and by $\mathrm{D}\left({ }^{2} \mathrm{~S}\right)$ from $\mathrm{DI}$ photodissociation at $\sim 243 \mathrm{~nm}$. The radius of the ring is proportional to the velocity of the products, so after calibration at one radius the kinetic energy release corresponding to all other rings is determined. At least 2 rings are seen in each image in Figure 2, each with a perpendicular $\left(\sim \sin ^{2} \theta\right.$, with $\theta=0^{\circ}$ defined at the top center axis of the image) angular distribution. An overview of the velocity information extracted for each observed 
ring is presented in Table 2. As required from momentum balance, the $\mathrm{O}$ images from $O D$ photodissociation are larger (in the proper ratio) than those from $\mathrm{OH}$ photodissociation at the same energy, which is an additional proof that the images originate from $\mathrm{OH} / \mathrm{OD}$.

Raw (hexapole on-off) $\left.\mathrm{O}^{3} \mathrm{P}_{\mathrm{J}}\right){ }^{+}$images produced by photodissociation of $\mathrm{OH}$ and $\mathrm{OD}$ at $\sim 226 \mathrm{~nm}$ are presented in Fig. 2a) and b), respectively, and a raw $D\left({ }^{2} S\right)^{+}$image (hexapole on-hexapole off) produced by photodissociation of OD at $\sim 243 \mathrm{~nm}$ is presented in Fig. $2 \mathrm{c}$ ). All of these images are summations of 50000 laser shots. The background-induced signal at the center of the images is not fully eliminated by the hexapole on-off subtraction scheme, causing a slight overload of the CCD camera at this position, especially for the $\mathrm{O}\left({ }^{3} \mathrm{P}_{2}\right)$ images. Raw $\mathrm{O}\left({ }^{3} \mathrm{P}_{\mathrm{J}}\right)$ images for photodissociation of $\mathrm{OH}$ and $\mathrm{OD}$ at $200 \mathrm{~nm}$ which are taken using event counting and only with the hexapole 'on' are shown in Fig. 2a') and $\left.b^{\prime}\right)$, respectively. In Fig. $\left.2 c^{\prime}\right)$ a raw (hexapole on-hexapole off) $D\left({ }^{2} S\right)^{+}$image produced by photodissociation of OD at $\sim 205 \mathrm{~nm}$ is presented. The $\mathrm{O}^{+}$images from $\mathrm{OH}$ are summations of 90000 laser shots, and the $\mathrm{O}^{+}$and $\mathrm{D}^{+}$images from OD are summations of 230000 laser shots.

Direct detection of $O\left({ }^{1} D_{2}\right)$ products from the dissociation of OD using $(2+1)$ REMPI via the ${ }^{1} \mathrm{P}_{1}$ state at $205.473 \mathrm{~nm}$ (vac.) was also attempted. While a small signal at the center of the image from $O\left({ }^{1} D\right)$ produced in the discharge was observed, we did not observe any convincing $O\left({ }^{1} D\right)$ signal from the photodissociation of OD at $205 \mathrm{~nm}$.

\section{2. $O\left({ }^{3} P_{J}\right)$ branching ratios}

Experimental branching ratios for the channels $\left[\mathrm{O}\left({ }^{3} \mathrm{P}_{2}\right)+\mathrm{H}\left({ }^{2} \mathrm{~S}\right)\right]:\left[\mathrm{O}\left({ }^{3} \mathrm{P}_{1}\right)+\mathrm{H}\left({ }^{2} \mathrm{~S}\right)\right]:\left[\mathrm{O}\left({ }^{3} \mathrm{P}_{0}\right)+\mathrm{H}\right.$ $\left.\left({ }^{2} \mathrm{~S}\right)\right]$ of $\mathrm{OH}$ and $\left[\mathrm{O}\left({ }^{3} \mathrm{P}_{2}\right)+\mathrm{D}\left({ }^{2} \mathrm{~S}\right)\right]:\left[\mathrm{O}\left({ }^{3} \mathrm{P}_{1}\right)+\mathrm{D}\left({ }^{2} \mathrm{~S}\right)\right]:\left[\mathrm{O}\left({ }^{3} \mathrm{P}_{0}\right)+\mathrm{D}\left({ }^{2} \mathrm{~S}\right)\right]$ of $\mathrm{OD}$ at $\sim 226$ and $\sim 200 \mathrm{~nm}$ are given in Table 3. The total $\mathrm{OH}$ photodissociation signal strength was determined for each raw image at constant laser pulse energy. For these one-laser experiments, the dissociation and detection laser 


\subsection{Velocity and Kinetic Energy Analysis and Assignment of the images}

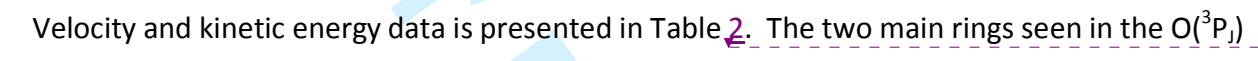

The corresponding kinetic energy distributions from these reconstructed images, extracted by integrating over all angles, are shown in Fig. 4. Weak signals due to $\mathrm{OH}$ are seen at lower kinetic 
energy in the $\mathrm{O}\left({ }^{3} \mathrm{P}_{2}\right)$ from $\mathrm{OD}$ image. The reconstructed images from $\mathrm{O}\left({ }^{3} \mathrm{P}_{2}\right) \mathrm{REMPI}$ at $\sim 226$ and $\sim 200$

$\mathrm{nm}$ arising from the photodissociation of $\mathrm{OH}$ are shown in Fig. 5, and the corresponding TKER curves

obtained from integrating over the angular distribution of the inverted images are shown in Fig. 6 . A

beam vibrational temperature is estimated from the relative peaks heights in the kinetic energy

distributions.

Each peak in the kinetic energy distribution can be assigned using the energy balance equation TKER $=h v+E(v i b)_{\mathrm{OH} / \mathrm{D}}-\mathrm{D}_{0}(\mathrm{OH} / \mathrm{OD})$, with the bond energy of $\mathrm{OH} / \mathrm{OD}, \mathrm{D}_{0}(\mathrm{OH} / \mathrm{OD})$, from references 3 , 33 , and 34 , and the recently calculated vibrational energies for ground $X^{2} \Pi$ state of OH/OD,

$\mathrm{E}(\mathrm{vib})_{\mathrm{OH} / \mathrm{D}}$ from Loo and Groenenboom $\frac{11}{\Delta{ }^{\prime}}$ Complementary first principle calculations (Fig. 1.) confirm Deleted: ${ }^{1}$ that one-photon excitation of $\mathrm{OH} / \mathrm{OD} X^{2} \Pi\left(v^{\prime \prime}\right)$ to the repulsive $1^{2} \Sigma^{-}$curve has a reasonably strong $\left(\sigma_{\max }>10^{-20} \mathrm{~cm}^{2}\right)$, wavelength-dependent photodissociation cross section in the $200-250 \mathrm{~nm}$ region. The two main rings seen for $\mathrm{O}\left({ }^{3} \mathrm{P}_{\mathrm{J}}\right)$ atom detection at $226 \mathrm{~nm}$ in Fig. 2a, for example, attributed in Table 2 to photodissociation of $\mathrm{OH}$ in vibrational levels $\mathrm{v}^{\prime \prime}=2$, and 3 , have photodissociation cross sections of $\sim 6.45 \times 10^{-20} \mathrm{~cm}^{2}$ and $\sim 3.22 \times 10^{-19} \mathrm{~cm}^{2}$, respectively. Depending on the dissociation/detection wavelength and the molecule (OH or OD), excitation of the $\mathrm{OH} X\left(\mathrm{v}^{\prime \prime}\right) \mathrm{v}^{\prime \prime}=1-4$ states are observed. We should point out that the vibrational energy of $\mathrm{OH}\left(\mathrm{v}^{\prime \prime}=3\right)$ is $10199.39 \mathrm{~cm}^{-1}$, which for a molecular beam temperature of $\sim 2000 \mathrm{~K}$ (see next section) has a population probability of only $2 \times 10^{-5}$.

\subsection{Temperature of the discharge beam}

The relative intensity of the peaks observed in the TKER curves of Figs. 3 and 5 can be qualitatively understood using the photodissociation cross sections computed for each $\mathrm{OH} X\left(\mathrm{v}^{\prime \prime}\right)$ vibrational state (Fig. 1). The relative peaks heights determined from the $\mathrm{O}\left({ }^{3} \mathrm{P}_{2}\right)$ and $\mathrm{D}\left({ }^{2} \mathrm{~S}\right)$ fragment atoms images for the higher energy regime, 200 and $\sim 205 \mathrm{~nm}$, respectively, were found to agree with calculated photodissociation yields for an OD molecular beam with a vibrational temperature of 
$2000 \mathrm{~K}$. While in our previous study $\frac{1}{\mathrm{~A}}$ a vibrational temperature of $\sim 1700 \mathrm{~K}$ was estimated, a

vibrational temperature of $2000 \mathrm{~K}$ agrees better with the present, more extensive, experimental

data. The effect of an electric discharge on the vibrational excitation, relaxation, and energy transfer of diatomic molecules in pulsed supersonic beams has been the subject of several previous

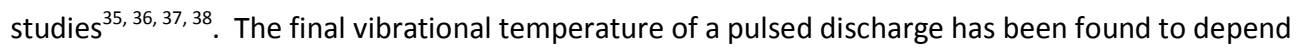
on a large number of experimental parameters, including backing pressure, buffer gas, discharge condition and geometry of the nozzle. Our experimental value compares reasonably with other studies of discharge sources. A discharge of NO in He produced an NO vibrational temperature of $6500 \mathrm{~K}$, for example $\frac{37}{1}$, while a similar discharge $\frac{38}{-1}$ in OCS produced an SO vibrational temperature of $\sim 1000 \mathrm{~K}$.

At a vibrational temperature of $2000 \mathrm{~K}$, the $\mathrm{v}^{\prime \prime}=1-3$ states of $\mathrm{OH}$ contains only $5,0.3$, and $0.002 \%$ of the total population. The sensitivity of the imaging experiment is thus quite high in order to image the neutral photodissociation products from such small fractions of the beam population. In our previous $2+1$ REMPI study ${ }^{16}$ of $\mathrm{OH}$ we were able to detect transitions from the $\left(v^{\prime \prime}=1,2,3\right)$ vibrational ly excited states to the higher lying $D^{2} \Sigma^{-}$and $3^{2} \Sigma^{-}$Rydberg states. We did not observe any $(2+1)$ REMPI transitions from vibrational levels higher than $v^{\prime \prime}=3$. Our previous study used the same $\mathrm{OH}$ source as in the present study and the REMPI spectra also confirmed that the $\mathrm{OH}$ radicals produced in the discharge source are indeed vibrationally hot, but rotationally quite cold $(<20 \mathrm{~K})$. The population in the excited rotational states is effectively relaxed in the supersonic expansion due to the relatively small rotational spacing but the vibrational spacing is too large to allow an efficient relaxation.

\subsection{Ion recoil effects on kinetic energy resolution}

Deleted: ${ }^{37}$

Formatted: Font: $11 \mathrm{pt}$, Complex Script Font: 11 pt, Superscript 
While ion recoil ${ }^{39,40,41}$ is deleterious in both $\mathrm{O}$ atom and $\mathrm{D}$ atom imaging, the $\mathrm{O}$ atom kinetic energy resolution is most affected, as is evident in the curves shown in Figure 4. Photodissociation of a state-selected diatomic molecule should lead to sharp peaks in the KER curves, while the observed peaks are quite broad. In our previous $\mathrm{OH}$ photodissociation study $\frac{1}{\mathbf{z}}$ we pointed out that the velocity resolution is limited by ion recoil from the $(2+1)$ REMPI detection process. The large excess ionization energy (3hv-IP) when partitioned by momentum conservation creates a high velocity electron and low, but non-zero, velocity fragment ion. This effect is most important for combined photodissociation and REMPI detection using the higher energy $\sim 200$ and $\sim 205$ nm photons. On conversion of the neutral fragments to ions, the ion recoil, a fixed and known velocity sphere, is added to the original velocity vector of the neutral $O\left({ }^{3} P_{J}\right)$ and $D\left({ }^{2} S\right)$ photofragments. While the added ion-recoil velocity is relatively small, it causes significant broadening when its magnitude approaches the velocity spacing of neighboring rings in the image. The percentage effect of ion recoil on the velocity of the nascent $\mathrm{O}$ or $\mathrm{D}$ fragment is roughly independent of the fragment mass because a higher mass atom ( $\mathrm{O}$ from $\mathrm{OH} / \mathrm{OD}$ ) has a lower nascent velocity due to the mass partitioning factor in the TKER equation.

In order to quantify the $\mathrm{O}$ atom ion recoil we have measured an $\mathrm{O}^{+}$image of cold (zero transverse velocity) $\mathrm{O}\left({ }^{3} \mathrm{P}_{2}\right)$ atoms created in the discharge beam. A magnification lens similar to that of reference 42 was used to magnify the image of low velocity $\mathrm{O}^{+}$to observe the ion-recoil effect. $\mathrm{O}\left({ }^{3} \mathrm{P}_{2}\right)$ ion-recoil is characterized as a mixed perpendicular angular distribution $\left(\beta^{\sim}-0.2\right)$, which causes significant broadening of the $O / D$ atom signal, especially along $\theta=90^{\circ}$, where $\theta$ is the angle between the recoil velocity vector and the polarization direction of the linearly polarized REMPI laser. This anisotropic broadening is added to each velocity component of the perpendicular $(\Sigma \leftarrow \Pi)$ angular distribution.

The two-photon excited $\mathrm{n}=2$ s electron in the (2+1) REMPI of D ( $\left.{ }^{2} \mathrm{~S}\right)$ atoms at $\sim 243$ and $\sim 205 \mathrm{~nm}$ is ejected as a $p$ wave, thus with a pure parallel or $\cos ^{2} \theta$ distribution. This causes an observable 


\subsection{Angular distributions}

Angular distributions, $I(\theta)$, were obtained by integrating the inverted image over the velocity range (which includes the ion-recoil spreading) of each ring, These are fitted to the expression: $I(\theta)$ $\sim 1+\beta P_{2}(\cos \theta)+\gamma P_{4}(\cos \theta)$ where $P_{2}(\cos \theta)$ and $P_{4}(\cos \theta)$ are the second- and fourth-order Legendre polynomials, respectively, and $\beta$ and $\gamma$ are anisotropy parameters. In the absence of alignment in the probed fragment, the anisotropy parameter $\beta(-1 \leq \beta \leq+2)$ is -1 for a pure perpendicular transition and +2 for a pure parallel transition. These extreme values of $\beta$ can only be obtained if the dissociation lifetime $\tau$ of the excited state is much shorter than the rotation period, $\tau_{\text {rot }}$ of the parent molecule (direct axial dissociation). In the absence of product atom alignment $\left(\mathrm{O}^{3} \mathrm{P}\right.$ products) the anisotropy parameter $\gamma=0$. When atomic alignment is present and probed by the 
linearly polarized REMPI laser, both $\beta$ and $\gamma$ are necessary to fit the angular distributions, as is described in the sudden limit analysis.

A perpendicular transition from the ground $X^{2} \Pi$ state to the directly dissociative $1^{2} \Sigma$ - electronic state should yield $\beta=-1$. As is obvious from Fig. 2, all of the observed angular distributions are roughly perpendicular. For the stronger rings in the $D\left({ }^{2} S\right)$ atom images for photodissociation of $O D$ at $\sim 243$ and also at $\sim 205 \mathrm{~nm}$, an almost fully perpendicular angular distribution is observed. As discussed in the next section, a fully perpendicular angular distribution $(\beta=-1)$ for photodissociation of $O D$ at $~ 243 \mathrm{~nm}$ was measured for the strongest ring in the $\mathrm{D}^{+}$image by applying Doppler-free $(2+1)$ REMPI, which is less sensitive to background D atoms than standard $(2+1)$ REMPI.

Representative angular distributions for the strongest peaks of the dissociation products $O\left({ }^{3} \mathrm{P}_{2,1,0}\right)$ from $\mathrm{OH} / \mathrm{OD}$ at 226 and $200 \mathrm{~nm}$ and $\mathrm{D}\left({ }^{2} \mathrm{~S}\right)$ from OD at 243 and $205 \mathrm{~nm}$ are shown in Fig. 7. Anisotropy parameters $\beta, \gamma$ determined from the angular distribution of $O\left({ }^{3} \mathrm{P}\right)$ fragments are given in Table 4. The estimated uncertainty of $\beta$ and $\gamma$ is typically 0.1 . Uncertainty values of $\beta$ or $\gamma$ exceeding 0.1 are indicated in the table. It is clear from Table 4 that the fine-structure dependent $\beta$ parameters at 226 and $200 \mathrm{~nm}$ deviate strongly from -1 for $\mathrm{O}\left({ }^{3} \mathrm{P}_{2,1}\right)$. Alignment of the $\mathrm{O}\left({ }^{3} \mathrm{P}_{2,1}\right)$ photofragments is observed as a dip in signal strength (corresponding to a negative $\gamma$ value) along the $\theta=90^{\circ}$ in the image. $\beta$ becomes more negative as the angular momentum $\mathrm{J}$ of the $O\left({ }^{3} \mathrm{P} \mathrm{J}\right)$ photofragments decreased and the value of the anisotropy parameter $\gamma$ increases with the decreasing values of $\beta$ over the fine structure levels. These trends are predicted by the sudden limit analysis in section 3 .

In Figure 8 the anisotropy parameters $\beta$ and $\gamma$ from Table 4 are plotted as a function of dissociation wavelength. It can be seen from this figure that the anisotropy parameters of the three $\mathrm{O}\left({ }^{3} \mathrm{P}_{\mathrm{J}}\right)$ channels are different from each other, but there are no large variations in these parameters 
1

2

3

4

5

6

7

8

9

10

11

12

13

(within the experimental error limit) as a function of excitation energy at $\sim 226$ and $\sim 200 \mathrm{~nm}$. There is also no significant variation in the $\beta$ parameter for $D$ atoms from OD photodissociation at $243 \mathrm{~nm}$ compared to $205 \mathrm{~nm}$.

\subsection{Doppler-free Imaging}

Another origin of ring broadening is space charge, which occurs when the laser-created ion density is too large. On increasing the laser power as much as possible to obtain a reasonable photofragment signal we also ionize non-signal species which further increases space charge. To decrease this effect and also avoid errors in scanning over the Doppler profile when taking the image, we apply the Doppler-free $(2+1) \mathrm{REMPI}^{44}$ to probe the $\mathrm{D}$ atom products from photodissociation of OD. In our configuration we used two counter-propagating linearly polarized laser beams to ionize the $\mathrm{D}\left(1 \mathrm{~s}^{2} \mathrm{~S}\right)$ atoms by $(2+1)$ REMPI through the $\mathrm{D}\left(2 \mathrm{~s}^{2} \mathrm{~S}\right)$ state at the center wavelength of $243.09 \mathrm{~nm}$. The laser light at $243.09 \mathrm{~nm}\left(\sim 1.5 \mathrm{~mJ} /\right.$ pulse, $5 \mathrm{~ns}$ pulse length, $0.4 \mathrm{~cm}^{-1}$ bandwidth) is tuned to the center of the Doppler profile and focused with a $20 \mathrm{~cm}$ lens onto the molecular beam. The laser beam was retro-reflected with a $25 \mathrm{~cm}$ focal length spherical mirror and refocused onto the molecular beam. The polarization vector of the both beams was parallel to the detector face. Note that this configuration is not optimal, there is a $50 \mathrm{~cm}(\sim 2 \mathrm{~ns})$ delay between the two beams, and the laser bandwidth is also much broader than desired for optimal Doppler-free detection. When the two beams overlap spatially the total signal increased by a factor of $\sim 15$, which allowed the use of lower laser power and thus resulted in less space charge and background effects. The Doppler-free condition ensures detection of all velocity components with equal sensitivity, but the two single-beam signals which are always present strongly favor detection of the zero velocity atoms from the discharge, which appear in the center of the image. The D atom Doppler-free signal is not disturbed by the zero velocity signals in the middle of the image. 
The Doppler free raw image of $D\left({ }^{2} S\right)$ and the corresponding slice through the inverted 3-D image are presented in Fig. 9. By this method a pure perpendicular angular distribution was measured for the strongest ring in $D$ atom image $(\beta=-1.0+/-0.1)$

\subsection{Effect of parent molecule orientation and alignment}

Our experimental conditions, i.e., a molecular beam passing through a hexapole state selector into a static electric field, are similar to those used for studies of the photodissociation of oriented $\mathrm{CH}_{3}$ I molecules ${ }^{45}$ or orientation effects in $\mathrm{OH}$ inelastic collisions ${ }^{46}$. On exiting the hexapole the $f$-state selected $\mathrm{OH}$ molecules $\left(\Omega=3 / 2, \mathrm{~J}=3 / 2, \mathrm{M}_{\mathrm{J}}=3 / 2,1 / 2\right)$ fly $5 \mathrm{~cm}$ before passing through a $4 \mathrm{~mm}$ hole in the center of the repeller plate electrode, which is biased typically at -3000V. Due to this large repeller plate opening and single hexapole configuration we estimate that at about $60 \%$ of the $\mathrm{OH}$ molecules studied are in the $M_{j}=1 / 2$ state. Within the imaging lens, at the point where photodissociation and photoionization takes place, the static field is $\sim 710 \mathrm{~V} / \mathrm{cm}$. While this is a rather low field, it causes parity mixing of the $e$ and $f$ levels and a slight pre-orientation of the stateselected $\mathrm{OH}_{4}^{46}$ Parity mixing is observable in the REMPI and LIF spectra of the state-selected $\mathrm{OH}$, and can be avoided by pulsing on the velocity mapping field after laser excitation and ionization has Formatted: English U.K. Deleted: ${ }^{45}$ taken place. Pre-orientation of the $\mathrm{M}_{\mathrm{J}}=1 / 2$ state is negligible at $710 \mathrm{~V} / \mathrm{cm}$, and pre-orientation of the $M_{j}=3 / 2$ state caused by this field is not observable in a photodissociation process because the orientation field is parallel with the ion TOF direction. Information mapped along the TOF direction is lost in the 'crush' of the 3D image onto the 2D detector. Our $\mathrm{OH}$ sample used for photodissociation imaging is thus effectively isotropic within our data uncertainties, which means we can assume cylindrical symmetry around the laser polarization direction in order to analyze the raw images using standard inversion procedures (Basex program) $)_{12}^{32}$

\section{DISCUSSION}


The sudden-limit analysis of section 3 assumes a single state (the $1^{2} \Sigma^{-}$state) is optically prepared in the Franck-Condon region of the $\mathrm{OH}$ molecule. Lee $\frac{15}{15}$ has argued that in the high-energy region between the first and second dissociation thresholds of $\mathrm{OH}$ that predissociative levels of the $A^{2} \Sigma$ $\left(v^{\prime} \geq 7\right)$ state can also be accessed from the $v^{\prime \prime}=0$ level of the ground state, and interference from the predissociative and direct dissociation pathways could cause a strong local variation in the $O\left({ }^{3} \mathrm{P} J\right)$ fine structure branching ratios. By tuning the dissociation laser wavelength, the desired $\mathrm{O}\left({ }^{3} \mathrm{P}_{\mathrm{J}}\right)$ product atom can then be selected in a type of internal coherent control method. In our experiment excitation takes place from $\mathrm{OH} X\left(\mathrm{~N}^{\prime \prime}=1, \mathrm{~J}^{\prime \prime}=3 / 2, \mathrm{v}^{\prime \prime}=0-5\right)$ at the dissociation wavelengths $243,226,205$, and $200 \mathrm{~nm}$. A number of $A^{2} \Sigma^{-}\left(v^{\prime} \geq 7\right)$ states lie in the $243-200 \mathrm{~nm}$ region when starting from $X$ $\left(v^{\prime \prime}=0-4\right)$, but none are close to resonance with the specific $\mathrm{O}, \mathrm{H}$, or D atom REMPI lines we employ. Excitation beginning from higher vibrational levels of the $X$ state probes progressively larger internuclear distances, which favors excitation to the repulsive $1^{2} \Sigma$ state over excitation to bound levels of the $A^{2} \Sigma^{-}$state. To produce the predicted branching ratio variations, the contributions from the two indistinguishable dissociation pathways should be roughly comparable. We believe that excitation to bound levels of the $A^{2} \Sigma^{-}$state is extremely weak at our photodissociation wavelengths so that the photodissociation dynamics is reduced to that on the single $1^{2} \Sigma^{-}$state. Zhou et al. $\frac{10}{2}$ come to a similar conclusion in an investigation of the photodissociation dynamics of the isovalent 


\section{CONCLUSION}

Formatted: Complex Script Font:

Zhou et. al. $\frac{10}{y}$ studied the photodissociation dynamics of jet-cooled $\mathrm{SH}$ in the photolysis wavelength region of 216 to $232 \mathrm{~nm}$ using the high-n Rydberg atom time of flight technique. Their results also indicate that UV photolysis of $\mathrm{SH}$ is a due to one photon-direct dissociation of $\mathrm{SH}$ to the dissociative $1^{2} \Sigma$ curve from the ground state of $\mathrm{SH}\left(X^{2} \Pi, \mathrm{v}^{\prime \prime}=0-2\right)$. Their product fine structure states distributions also showed that the $S\left({ }^{3} \mathrm{P}_{\mathrm{J}}\right)$ spin -orbit branching fractions of $\mathrm{SH}$ are close to the 5:3:1 sudden limit distribution from the single $1^{2} \Sigma$ state, as in the case of $\mathrm{OH}$. Their experimental $\beta$ parameters for the three spin-orbit products $S\left({ }^{3} P_{J}\right)$ have the same $\sim-1$ value in the $216-232 \mathrm{~nm}$ region, which is similar to the results from this present study (for $O\left({ }^{3} P_{0}\right)$ and $D\left({ }^{2} S\right)$ ) where the anisotropy parameters are also nearly energy-independent. We should also point out that our uncertainties in branching ratios and angular distribution parameters are relatively large, due to the very small populations of the vibrationally excited molecules studied in this work. Good agreement is found for the sudden limit predictions, but it would still be worthwhile to use a different experimental approach (such as VUV photodissociation) in order to obtain a higher experimental precision for a more stringent comparison with theory. 


\section{ACKNOWLEDGMENTS}

This work is part of the research program of the "Stichting voor Fundamenteel Ondrezoek der Materie (FOM)," which is financially supported by the "Nederlandse Organisatie voor 
Wetenschappelijk Onderzoek (NWO)." The ab initio work has been financially supported by the Council for Chemical Sciences of the Netherlands Organization for Scientific Research (CW-NWO).

ouncil for Chemical Sciences of the Netherands Organization for Scientic Research (CW-NWO). 


\section{FIGURE CAPTIONS}

Figure 1: Potential energy diagram of the $\mathrm{OH}$ electronic states relevant for this study. On the left side of the figure are photodissociation cross sections for excitation from the vibrational levels $v^{\prime \prime}=0,2$ and 3 of the ground $\left(X^{2} \Pi\right)$ electronic state to the repulsive $1^{2} \Sigma$ state of $\mathrm{OH}$ from 100 to $350 \mathrm{~nm}$. The vertical arrows represent one-photon dissociation at $\sim 200 \mathrm{~nm}$ of the repulsive $1^{2} \Sigma$ state from the vibrational levels $v^{\prime \prime}=2$ and 3 of the ground state of $\mathrm{OH}$. At $200 \mathrm{~nm}$, for example, the photodissociation cross section from $\mathrm{v}^{\prime \prime}=2$ is larger than that from $v^{\prime \prime}=3$.

Figure 2: Raw $\mathrm{O}^{+}$images produced by one-photon photodissociation of: (a) $\mathrm{OH}$ and (b) OD. The $\mathrm{O}\left(2 \mathrm{p}^{3} \mathrm{P}_{\mathrm{J}}\right)$ $(\mathrm{J}=2,1,0)$ atoms were ionized by $(2+1)$ REMPI through the $\mathrm{O}\left(3 \mathrm{p}^{3} \mathrm{P}_{\mathrm{J}}\right)$ states (images a) and b)) at $\sim 226 \mathrm{~nm}$, and by $(2+1)$ REMPI through the $\mathrm{O}\left(4 \mathrm{p}^{3} \mathrm{P}_{\mathrm{J}}\right)$ states (images $\left.\mathrm{a}^{\prime}\right)$ and $\left.\left.\mathrm{b}^{\prime}\right)\right)$ at $\sim 200 \mathrm{~nm}$. Raw images of $\mathrm{D}^{+}$from the one photon dissociation of OD formed from $D\left(1 s^{2} S\right)$ atoms by (2+1) REMPI through the: (c) $D\left(2 s^{2} S\right)$ state at the wavelength $243.09 \mathrm{~nm}$ and $\left(c^{\prime}\right) \mathrm{D}\left(3 \mathrm{~s}^{2} \mathrm{~S}\right)$ states at $205.07 \mathrm{~nm}$. A grayscale bar (left side) shows the relative signal intensity, where the darker areas correspond to higher signal. The dot in the center of each image corresponds to zero-velocity fragment $\mathrm{O}\left({ }^{3} \mathrm{P}_{\mathrm{J}}\right)$ or $\mathrm{D}\left({ }^{2} \mathrm{~S}\right)$ atoms formed in the discharge source. The outer rings originate from photodissociation of vibrationally excited $\mathrm{OH} / \mathrm{OD} \mathrm{X}^{2} \Pi$ radicals. The vertical arrow $(\uparrow)$ indicates the direction of the laser polarization.

Figure 3: Abel inverted images of: (a) $O\left({ }^{3} \mathrm{P}_{2}\right),\left(\right.$ b) $D\left({ }^{2} \mathrm{~S}\right)$ formed from the one photon dissociation of vibrationally excited OD $X^{2} \Pi$ radicals at $\sim 200$ and $\sim 205 \mathrm{~nm}$, respectively. On the left side a intensity grey-scale is presented. On the right side the vertical arrow $(\downarrow)$ presenting the laser polarization. The $\mathrm{O}^{3} \mathrm{P}$ image is smaller than the D image, it has been scaled to the same size for comparison. Note that the weak extra inner rings in the $\mathrm{O}^{3} \mathrm{P}$ images for $\mathrm{OD}$ come from an $\mathrm{OH}$ impurity.

Figure 4: Total kinetic energy release (TKER) distribution for the images shown in Figure 3.The initial vibrational state of $O D$ is determined from energy balance with TKER $=h v+E(v i b) O D-D O(O D)$. The bar graphs show the calculated photodissociation yields for OD X $2 \Pi(v)$ at a vibrational temperature of $2000 \mathrm{~K}$. 
Figure 5: Abel inverted images of $\left.\mathrm{O}^{3} \mathrm{P}_{2}\right)$ formed from the one photon dissociation of vibrationally excited $\mathrm{OH} \mathrm{X}^{2} \Pi$ radicals at: (a) $~ 226$ and (b) $\sim 200 \mathrm{~nm}$, respectively( rescaled to same size). See figure caption 2 for other details.

Figure 6: Total kinetic energy release (TKER) distribution for the images shown in Figure 5. The initial vibrational state of $\mathrm{OH}$ is determined from energy balance with TKER $=\mathrm{hv}+\mathrm{E}(\mathrm{vib})_{\mathrm{OH}}-\mathrm{D}_{0}(\mathrm{OH})$. The bar graphs show the calculated photodissociation yields for $\mathrm{OH} \mathrm{X}^{2} \Pi(\mathrm{v})$ at a vibrational temperature of $2000 \mathrm{~K}$.

Figure 7: The measured angular distribution and fitted curves for the strongest peaks of the dissociation products $\mathrm{O}\left({ }^{3} \mathrm{P}_{2,1,0}\right)$ coming from one photon dissociation of: a) $\mathrm{OH}$ at $\sim 226$ (upper panel) and $\sim 200 \mathrm{~nm}$ (lower panel); b) OD at 226 (upper panel) and $\sim 200 \mathrm{~nm}$ (lower panel) and c) The measured angular distribution and fitted curves for the strongest peaks of the dissociation products $D(2 S)$ coming from one photon dissociation of: $O D$ at $\sim 243$ and $\sim 205 \mathrm{~nm}$, respectively. The angular distribution is fit to the expression: $1(\theta)=1+\beta P_{2}(\cos \theta)$ $+\gamma P_{4}(\cos \theta)$.

Figure 8: Experimental $\beta$ and $\gamma$ values plotted as a function of wavelength ( 226 and $\sim 200 \mathrm{~nm}$ ) corresponding to the different fine structure states of the $O\left({ }^{3} \mathrm{P}_{\mathrm{J}}\right)$ atom $(J=2,1,0)$ from photodissociation of $\mathrm{OH}$ and OD. $\quad \beta$ and $\gamma$ with experimental error bars are represented by a filled square for $\mathrm{OH}$ and by a filled triangle for OD. Calculated anisotropy parameters $\beta$ and $\gamma$ in the sudden-recoil limit, characterizing the angular distribution of $O\left({ }^{3} \mathrm{P}_{\mathrm{J}}\right)$ (with $\left.\mathrm{J}=2,1,0\right)$ photofragments formed in the one photon process photodissociation of $\mathrm{OH} / \mathrm{OD}$ via the $1^{2} \Sigma^{-}$state are represented by a hollow square.

Figure 9: The Doppler- free (a) and corresponding Abel inverted image (b) of $D\left({ }^{2} S\right)$ formed from the one photon dissociation of vibrationally excited OD $X^{2} \Pi$ radicals at $\sim 243 \mathrm{~nm}$. See figure 3 for other details. 


\section{TABLES and CAPTIONS}

Table I: The sudden recoil limit for the $\mathrm{OH} \quad \mathrm{X}(2 \mathrm{C})+\mathrm{hv} \rightarrow 12 \Sigma-\rightarrow \mathrm{H}(2 \mathrm{~S})+\mathrm{O}(3 \mathrm{PJ})$ direct dissociation.

Columns 3-5 give the populations pJw. The symbols are defined in Sec. 3.2.

\begin{tabular}{|c|c|c|c|c|c|c|c|c|}
\hline $\mathrm{J}$ & $p_{J}$ & & I $\omega$ & & $\bar{p}_{0}{ }^{2}$ & $r_{j}$ & $\beta_{\mathrm{J}}$ & $\gamma_{J}$ \\
\hline & & 0 & 1 & 2 & & & & \\
\hline 0 & $1 / 9$ & $1 / 9$ & & & & $1 / 8$ & -1 & \\
\hline 1 & $1 / 3$ & 0 & $1 / 6$ & & $1 / \sqrt{2}$ & $27 / 80$ & $-5 / 7$ & $-2 / 7$ \\
\hline 2 & $5 / 9$ & $2 / 9$ & $1 / 6$ & 0 & $-\sqrt{7}$ & $43 / 80$ & $-25 / 43$ & $-18 / 43$ \\
\hline
\end{tabular}

Deleted: 2 
Table2. Experimentally observed and calculated fragment recoil velocity, velocity uncertainty, kinetic energy and ion-recoil velocity for photodissociation of $\mathrm{OH}$ and OD at 243, 226, 205, and $200 \mathrm{~nm}$.

\begin{tabular}{|c|c|c|c|c|c|c|c|c|c|}
\hline Parent & Frag. & $\begin{array}{r}\lambda_{\text {diss }} \\
(\mathrm{nm})\end{array}$ & Assign. & $\begin{array}{c}\text { TKER } \\
(\mathrm{eV})\end{array}$ & $\begin{array}{l}v_{\text {calc. }} \\
(\mathrm{m} / \mathrm{s})\end{array}$ & $\begin{array}{l}v_{\text {meas. }} \\
(\mathrm{m} / \mathrm{s})\end{array}$ & $\begin{array}{c}\Delta \mathrm{v} \\
(\mathrm{m} / \mathrm{s})\end{array}$ & $\begin{array}{c}\text { spacing } \\
(\mathrm{m} / \mathrm{s})\end{array}$ & $\begin{array}{l}v_{\text {recoil }} \\
(\mathrm{m} / \mathrm{s}) \\
\end{array}$ \\
\hline \multirow{2}{*}{$\mathrm{OH}$} & \multirow{2}{*}{$\mathrm{O}\left({ }^{3} \mathrm{P}_{\mathrm{J}}\right)$} & \multirow{2}{*}{226} & $\mathrm{v} "=2$ & 2.02 & 1173 & 1200 & \multirow{2}{*}{20} & \multirow{2}{*}{117} & \multirow{2}{*}{35} \\
\hline & & & $\mathrm{v"}=3$ & 2.39 & 1290 & 1300 & & & \\
\hline \multirow{2}{*}{ OD } & \multirow{2}{*}{$\mathrm{O}\left({ }^{3} \mathrm{P}_{\mathrm{J}}\right)$} & \multirow{2}{*}{226} & $\mathrm{v} "=3$ & 2.08 & 1622 & 1670 & \multirow{2}{*}{35} & \multirow{2}{*}{118} & \multirow{2}{*}{35} \\
\hline & & & $\mathrm{v"}=4$ & 2.32 & 1740 & 1765 & & & \\
\hline \multirow{3}{*}{$\mathrm{OH}$} & \multirow{3}{*}{$\mathrm{O}\left({ }^{3} \mathrm{P}_{\mathrm{J}}\right)$} & \multirow{3}{*}{200} & $\mathrm{v"}=1$ & 2.23 & 1252 & 1250 & \multirow{3}{*}{20} & \multirow{3}{*}{$\begin{array}{c}115 \\
98\end{array}$} & \multirow{3}{*}{45} \\
\hline & & & $\mathrm{v} "=2$ & 2.60 & 1367 & 1345 & & & \\
\hline & & & v"=3 & 3.08 & 1465 & 1475 & & & \\
\hline \multirow{3}{*}{ OD } & \multirow{3}{*}{$\mathrm{O}\left({ }^{3} \mathrm{P}_{\mathrm{J}}\right)$} & \multirow{3}{*}{200} & $\mathrm{v} "=2$ & 2.34 & 1774 & 1770 & \multirow{3}{*}{20} & \multirow{3}{*}{$\begin{array}{l}109 \\
103\end{array}$} & \multirow{3}{*}{45} \\
\hline & & & v"=3 & 2.64 & 1883 & 1870 & & & \\
\hline & & & v"=4 & 2.98 & 1986 & 1995 & & & \\
\hline \multirow{3}{*}{ OD } & \multirow{3}{*}{$\mathrm{D}\left({ }^{2} \mathrm{~S}\right)$} & \multirow{3}{*}{243} & v"=2 & 1.33 & 10420 & 10680 & \multirow{3}{*}{220} & \multirow{3}{*}{$\begin{array}{l}1185 \\
1040\end{array}$} & \multirow{3}{*}{212} \\
\hline & & & $\mathrm{v} "=3$ & 1.56 & 11605 & 11555 & & & \\
\hline & & & $\mathrm{v} "=4$ & 1.80 & 12650 & 12430 & & & \\
\hline \multirow{3}{*}{ OD } & \multirow{3}{*}{$\mathrm{D}\left({ }^{2} \mathrm{~S}\right)$} & \multirow{3}{*}{205} & $\mathrm{v"}=1$ & 1.80 & 12745 & 12425 & \multirow{3}{*}{230} & \multirow{3}{*}{$\begin{array}{l}920 \\
835\end{array}$} & \multirow{3}{*}{347} \\
\hline & & & $\mathrm{v"}=2$ & 2.16 & 13765 & 13610 & & & \\
\hline & & & $v^{\prime \prime}=3$ & 2.44 & 14685 & 14470 & & & \\
\hline
\end{tabular}



photodissociation of $\mathrm{OH}$ and $\mathrm{OD}$ at 226 and $200 \mathrm{~nm}$.

\section{Branching ratio}


Table 4. Top) Experimentally determined anisotropy parameters $\beta_{\exp }$ and $\gamma_{\exp }$ extracted for the strongest peaks seen in the background subtracted and fine structure state selected $\mathrm{O}^{+}$images for one-photon dissociation of $\mathrm{OH} / \mathrm{OD}$ at $\sim 226$ and $\sim 200 \mathrm{~nm}$. Middle) the corresponding anisotropy parameters $\beta_{\text {calc. }}$ and $\gamma$ calc, predicted theoretically, using the sudden limit analysis. Lower) Experimentally determined anisotropy parameters $\beta_{\text {exp }}$ extracted for the strongest peaks seen in the observed background subtracted $D^{+}$images coming from one-photon photodissociation of OD at $\sim 243$ and $\sim 205 \mathrm{~nm}$ and anisotropy parameters $\beta$ extracted for the strongest peaks seen in the Doppler free $D^{+}$image from one photon photodissociation of OD at $\sim 243 \mathrm{~nm}$. The estimated uncertainty of $\beta$ and $\gamma$ is 0.1 . Values of the uncertainties in $\beta$ and $\gamma$ which are larger than 0.1 are indicated in the table.

\begin{tabular}{|c|l|c|c|c|c|c|c|}
\hline \multicolumn{2}{|c|}{ Transition } & \multicolumn{2}{c|}{$\mathbf{O}\left({ }^{3} \mathbf{P}_{\mathbf{2}}\right)$} & \multicolumn{2}{c|}{$\mathbf{O}\left({ }^{3} \mathbf{P}_{\mathbf{1}}\right)$} & \multicolumn{2}{c|}{$\left.\mathbf{O}{ }^{3} \mathbf{P}_{\mathbf{0}}\right)$} \\
\cline { 3 - 8 } & $\boldsymbol{\beta}_{\exp }$ & $\gamma_{\exp }$ & $\boldsymbol{\beta}_{\exp }$ & $\gamma_{\exp }$ & $\boldsymbol{\beta}_{\exp }$ & $\gamma_{\exp }$ \\
\hline \multirow{2}{*}{$\mathbf{2 2 6} \mathbf{~ n m}$} & OH (v'=2) & -0.44 & -0.23 & -0.74 & -0.10 & -0.86 & +0.08 \\
\cline { 2 - 8 } & OD (v'=3) & -0.56 & -0.20 & -0.64 & +0.03 & -0.82 & -0.05 \\
\hline \multirow{2}{*}{$\mathbf{2 0 0} \mathbf{~ n m}$} & OH (v'=1) & -0.52 & $-0.43(15)$ & -0.65 & $-0.31(19)$ & $-0.94(51)$ & $-0.96(70)$ \\
\cline { 2 - 8 } & OD (v'=2) & $-0.61(16)$ & $-0.27(22)$ & $-0.67(18)$ & $-0.09(23)$ & $-0.99(65)$ & $+0.26(87)$ \\
\hline
\end{tabular}

\begin{tabular}{|c|c|c|c|c|c|c|}
\hline \multirow{4}{*}{$\mathbf{O}\left({ }^{3} \mathbf{P}_{2}\right)$} & \multicolumn{2}{c|}{$\mathbf{O}\left({ }^{3} \mathbf{P}_{1}\right)$} & \multicolumn{2}{c|}{$\mathbf{O}\left({ }^{3} \mathbf{P}_{0}\right)$} \\
\cline { 2 - 7 } Sudden limit analysis & $\boldsymbol{\beta}_{\text {calc. }}$ & $\gamma_{\text {calc. }}$ & $\boldsymbol{\beta}_{\text {calc. }}$ & $\gamma_{\text {calc. }}$ & $\boldsymbol{\beta}_{\text {calc. }}$ & $\gamma_{\text {calc. }}$ \\
\cline { 2 - 7 } & -0.58 & -0.42 & -0.71 & -0.28 & -1 & 0 \\
\cline { 2 - 7 }
\end{tabular}

\begin{tabular}{|c|c|c|c|}
\cline { 3 - 4 } \multicolumn{2}{c|}{} & $\mathbf{D}\left(^{2} \mathbf{S}\right)$ \\
\hline$\sim 243 \mathbf{~ n m}$ & $\begin{array}{c}\text { OD } \\
(\mathbf{v}=\mathbf{3})\end{array}$ & $\boldsymbol{\beta}_{\exp }$ & -1.06 \\
\hline$\sim \mathbf{2 0 5} \mathbf{~ n m}$ & $\begin{array}{c}\text { OD } \\
(\mathbf{v}=\mathbf{2})\end{array}$ & $\boldsymbol{\beta}_{\exp }$ & -1.02 \\
\hline
\end{tabular}




\section{REFERENCES}

${ }^{1}$ D. Č. Radenović, A. J. A. Van Roij, D. A. Chestakov, A. T. J. B. Eppink,

J. J. ter Meulen, D. H. Parker, M. P. J. Van der Loo, G. C. Groenenboom,

M. E. Greenslade, and M. I. Lester, J. Chem. Phys. 119, 9341 (2003).

${ }^{2}$ W. Zhou, Y. Yuan, and J. Zhang, J. Chem. Phys.119, 9989(2003)

${ }^{3}$ M. C. Abrams, S. P. Davis, M. L. P. Rao, and R. Engleman, Jr., J. Mol.

Spectrosc. 165, 57 (1994).

${ }^{4}$ E. F. Dishoeck and A. Dalgarno, J. Chem. Phys. 79, 873 (1983).

${ }^{5}$ W. G. Roberge, A. Dalgarno, and B. P. Flannery, Astrophys. J. 243, 817 (1981).

${ }^{6}$ E. F. van Dishoeck, S. R. Langhoff, and A. Dalgarno, J. Chem. Phys. 78, 4552 (1983).

${ }^{7}$ M. C. van Beek and J. J. ter Meulen, Chem. Phys. Lett. 337, 237(2001).

${ }^{8}$ A. T. J. B. Eppink and D. H. Parker, Rev. Sci. Instrum. 68, 3477(1997).

${ }^{9}$ L. M. C. Janssen, M. P. J. van der Loo, G. C. Groenenboom, S.-M. Wu, D. C. Radenovic, A. J. A. van Roij, I. A. Garcia, and D. H. Parker, J. Chem. Phys. 126, 094304 (2007).

${ }^{10}$ W. Zhou, Y. Yuan, S. Chen, and J. Zhang, J. Phys. Chem. 128, 054330 (2005). 
${ }^{11}$ M. P. J. Van der Loo and G. C. Groenenboom, J. Chem. Phys., 123, 074310 (2005).

${ }^{12}$ G. H. Dieke and H. M. Crosswhite, J. Quant. Radiat. Transfer 2, 97 (1962)

${ }^{13}$ D. R. Yarkony, J. Chem. Phys. 97, 1838 (1992).

${ }^{14}$ C. Kalyanaraman and N. Sathyamurthy, Chem. Phys. 187, 219 (1994).

${ }^{15}$ S. Y. Lee, J. Chem. Phys. 103, 3501 (1995).

${ }^{16}$ M.E. Greenslade, M. I. Lester, D. Č. Radenović, A. J. A. van Roij and D. H. Parker,

J. Chem. Phys.123 (2005) 074309.

${ }^{17} \mathrm{MOLPRO}$ is a package of $a b$ initio programs written by H.-J. Werner and

P. J. Knowles, with contributions from R. D.Amos, A. Berning, D. L.Cooper,

M. J. O. Deegan, A. J. Dobbyn, F. Eckert, C. Hampel, T. Leininger, R. Lindh,

W. Lloyd, W. Meyer, M. E. Mura, A. Nickla $\beta$, P.Palmieri, K. Peterson, R. Pitzer,

P. Pulay, G. Rauhut, M. Schutz, H. Stoll,A. J. Stone and T. Thorsteinsson

${ }^{18}$ P. J. Knowles and H.-J. Werner, Chem. Phys. Lett. 145, 514 (1988).

${ }^{19}$ H.-J. Werner and P. J. Knowles, J. Chem. Phys. 89, 5803 (1988).

${ }^{20}$ H.-J. Werner and P. J. Knowles, J. Chem. Phys. 82, 5053 (1985).

${ }^{21}$ P. J. Knowles and H.-J. Werner, Chem. Phys. Lett. 115, 259 (1985).

${ }^{22}$ D. T. Colbert and W. H. Miller, J. Chem. Phys. 96, 1982 (1992). 
${ }^{23}$ G. C. Groenenboom and D. T. Colbert, J. Chem. Phys. 99, 9681 (1993).

24 J. B. Lee and L. C. Nee J. Chem. Phys. 81, 31 (1984).

${ }^{25}$ M. C. G. N. van Vroonhoven and G. C. Groenenboom, J. Chem. Phys., 116, 1965 (2002).

${ }^{26}$ Y. Mo, H. Katayanagi, M. C. Heaven, and T. Suzuki, Phys. Rev. Lett. 77, 830 (1996).

${ }^{27}$ S. J. Singer, K. F. Freed, and Y. B. Band, J. Chem. Phys. 79, 6060 (1983).

${ }^{28}$ K. Schreel and J. J. ter Meulen, J. Phys. Chem. A 101, 7639 (1997).

${ }^{29}$ J. Luque and D. R. Crosley, "LIFBASE: Database and Spectral Simulation

Program (Version 1.5)," SRI International Report No. MP 99-009 (1999).

${ }^{30}$ E. de Beer, M. P. Koopmans, C. A. De Lange, Y. Wang, and W. A. Chupka, J. Chem. Phys. 94, 7634 (1991).

${ }^{31}$ A. M. Coroiu, D. H. Parker, G. C. Groenenboom, J. Barr, I. T. Novalbos and B. J. Whitaker, Eur. Journal Physics D, 38, 151 (2006).

${ }^{32}$ V. Dribinski, A. Ossadtchi, V.A. Mandelshtam, H. Reisler, Rev. Sci. Instrum. 73, 2634 (2002).

${ }^{33}$ C. Carlone and F. Dalby, Can. J. Phys. 47, 1945 (1969).

${ }^{34}$ B. Ruscic, D. Feller, D. A. Dixon, K. A. Peterson, L. B. Harding, R. L. Asher, and A. F. Wagner, J. Phys. Chem. A 105, 1(2001).

${ }^{35}$ M. Cacciatore, M. Capitelli, S. De Benedictis, M. Dilonardo, and C. Gorse, Topics 
in Current Physics 39, 5 (1986); M. Capitelli, C. Gorse, and A. Ricard, ibid. 39,

315 (1986).

${ }^{36}$ J. Fleniken, Y. Kim and H. Meyer, Chem. Phys. Lett. 318, 529 (2000).

${ }^{37}$ G. B. Courreges-Lacoste, J. P. Sprengers, J. Bulthuis, S. Stolte, T. Motylewski, and H. Linnartz, Chem. Phys. Lett. 335, 209 (2001).

${ }^{38}$ M. E. Sanz, M.C. McCarthy, and P. Thaddeus, J. Chem. Phys.119, 11715 (2003).

${ }^{39}$ D.H. Parker, R.F. Delmdahl, B.B.L.G. Bakker and H.P. Loock. J. Chin. Chem. Soc. 48327 (2001).

${ }^{40}$ S. Manzhos, H.-P. Loock, B.L.G. Bakker and D.H. Parker. J. Chem. Phys. 117

(2002) 9347.

${ }^{41}$ R. L. Toomes, P. C. Samartzis, T. P. Rakitzis and T. N. Kitsopoulos Chem. Phys. 301

(2004) 209.

${ }^{42}$ H. L. Offerhaus, C. Nicole, F. Lépine, C. Bordas, F.Rosca-Pruna and M. J. J. Vrakking, Rev. Sci. Instrum. 72, 3245 (2001).

${ }^{43}$ M. L. Lipciuc and M. H. M. Janssen, Phys. Chem. Chem. Phys.,8, 3007 (2006); D. A. Chestakov, M. Wu, G. Wu, A. T. J. B. Eppink, D. H. Parker and T. N. Kitsopolous, J. Phys. Chem A, 108, 8100 (2004).

${ }^{44}$ A. E. Pomerantz and R. N. Zare, Chem. Phys. Lett. 370, 515(2003)

Formatted: Font: Calibri, $11 \mathrm{pt}$ Complex Script Font: $11 \mathrm{pt}$

Formatted: Font: Calibri, $11 \mathrm{pt}$ Bold, Complex Script Font: $11 \mathrm{pt}$ Formatted: Font: Calibri, $11 \mathrm{pt}$, Complex Script Font: $11 \mathrm{pt}$

Formatted: Font: $11 \mathrm{pt}$, Complex Script Font: $11 \mathrm{pt}$

Formatted: Font: $11 \mathrm{pt}$

Formatted: Normal, Don't adjust right indent when grid is defined,

Don't adjust space between Latin and Asian text, Don't adjust space between Asian text and numbers

Formatted: English U.S. 
${ }^{45}$ T. P. Rakitzis, A.J. van den Brom, M.H.M. Janssen, Science 303, 1852 (2004).

${ }^{46}$ M. C. van Beek, J. J. ter Meulen and M.H. Alexander, J. Chem. Phys.113, 637 (2000).

${ }^{47}$ S. Y. Lee, J. Chem. Phys. 111, 6407 (1999). 


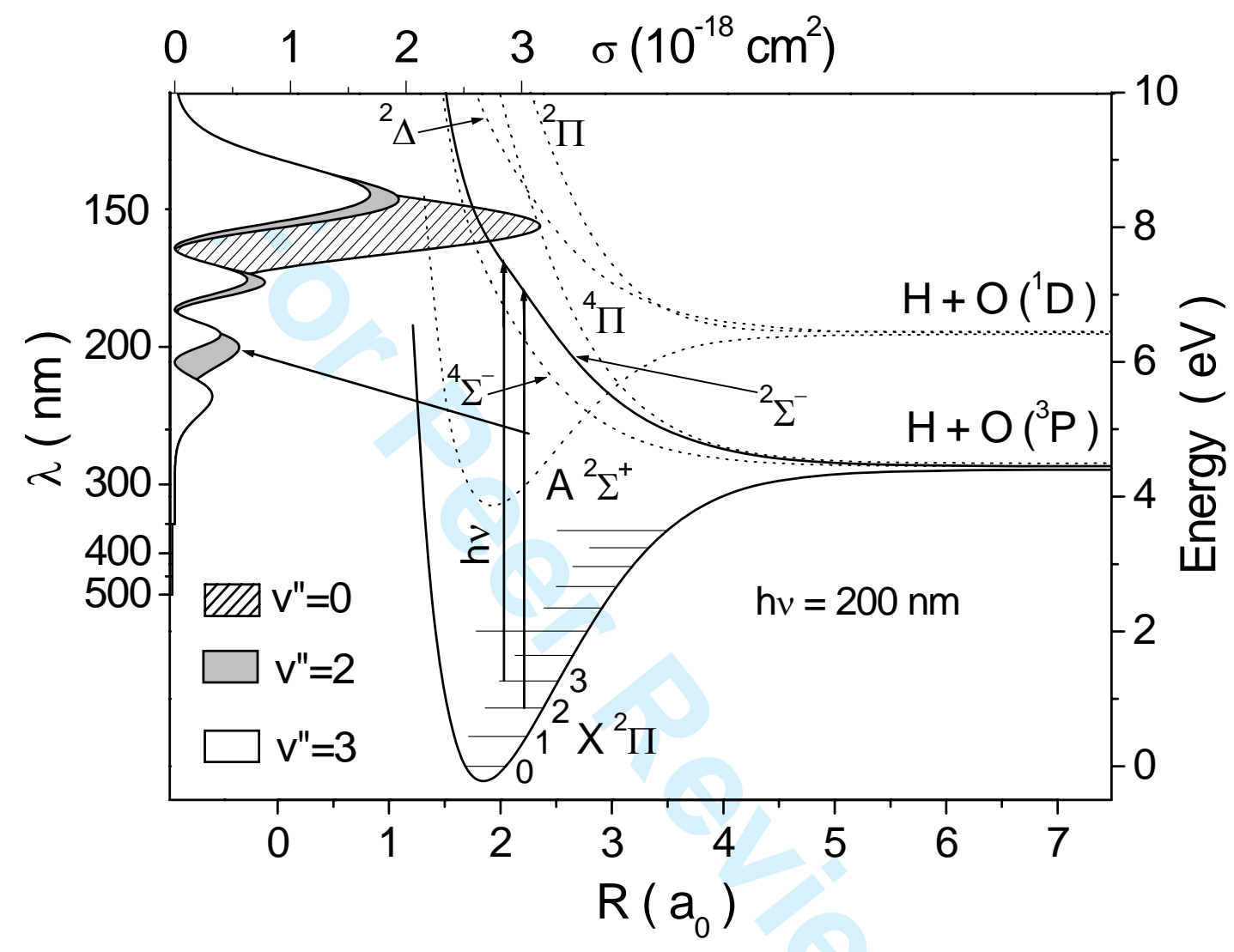

Figure 1 Radenovic et al. 


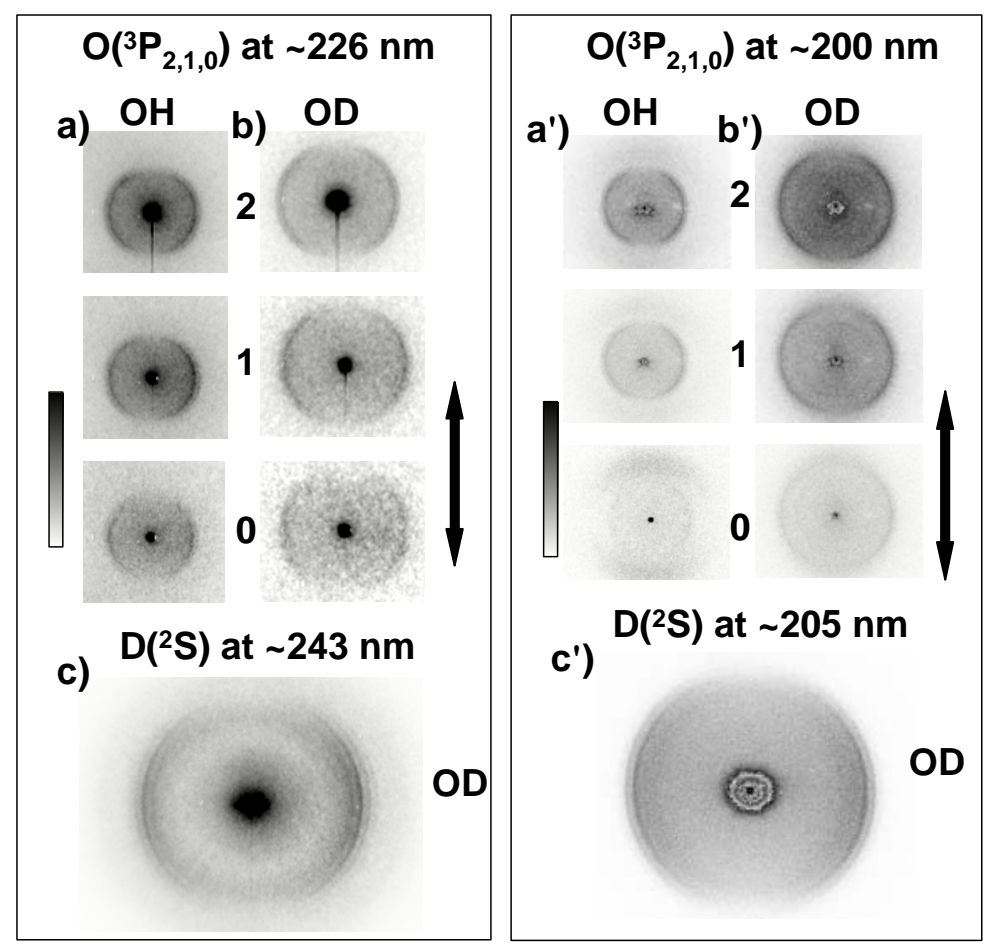

Fig. 2 Radenovic et al. 


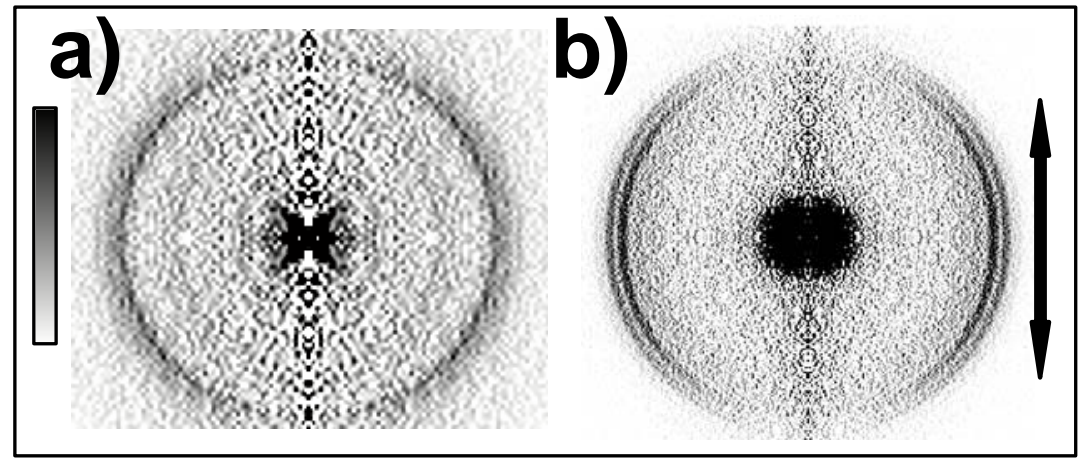

Figure 3 Radenovic et al.

1
2
3
4
5
6
7
8
9
10
11
12
13
14
15
16
17
18
19
20
21
22
23
24
25
26
27
28
29
30
31
32
33
34
35
36
37
38
39
40
41
42
43
44
45
46
47
48
49
50
51
52
53
54
55
56
57
58
59
60

Figure 3 Radenovic et al.

URL: http://mc.manuscriptcentral.com/tandf/tmph 


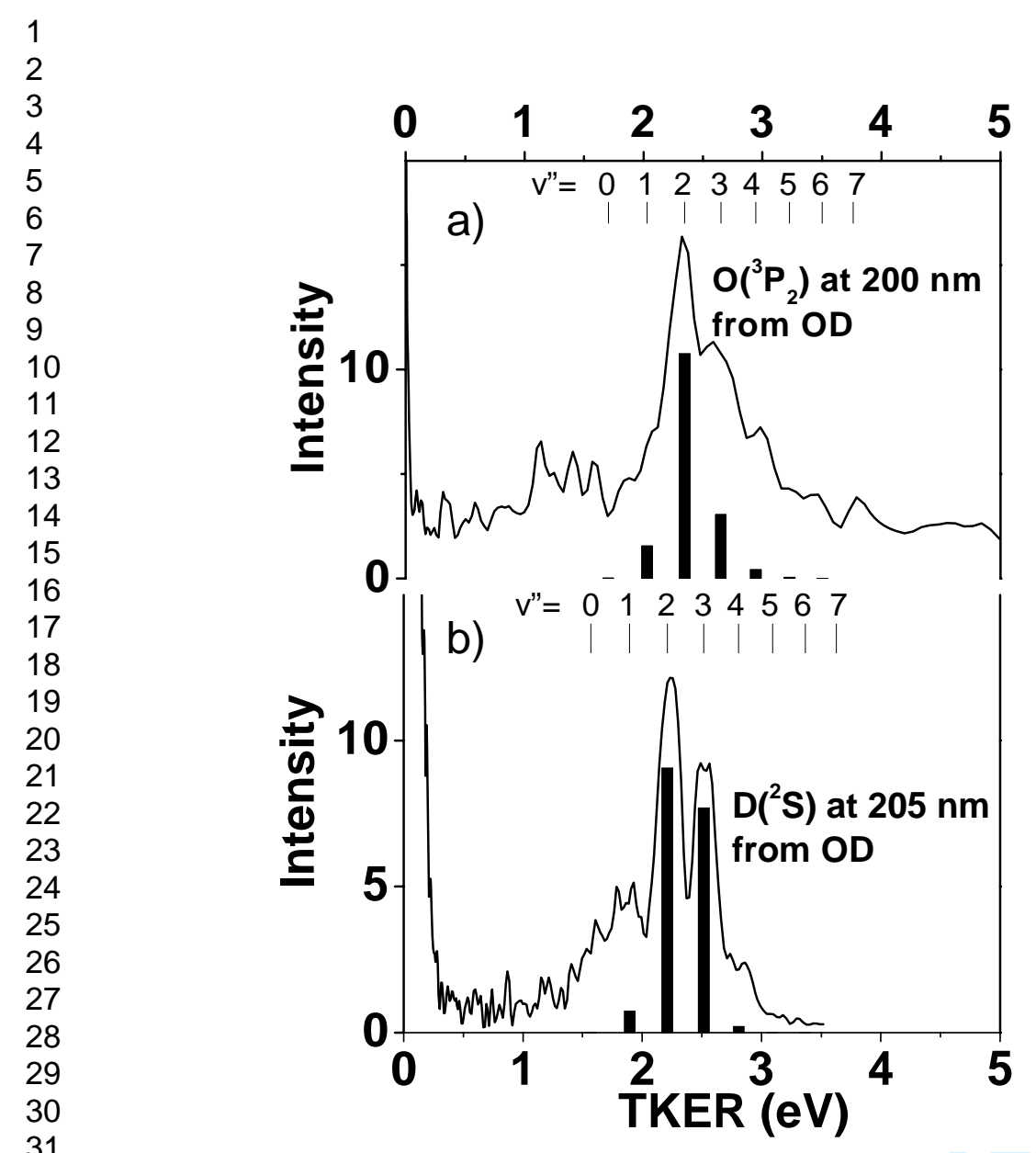

Figure 4. Radenovic et al. 


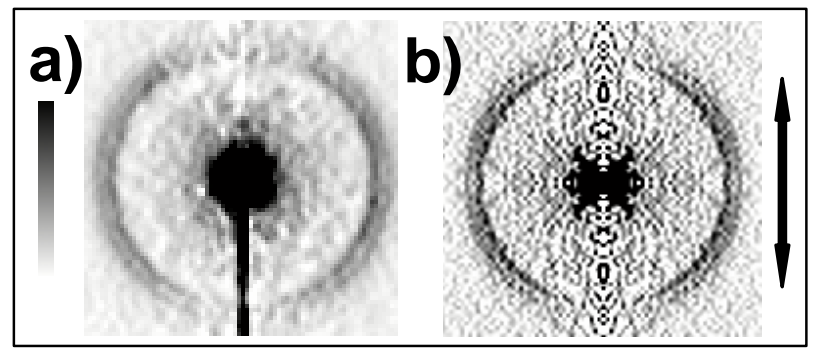

Figure 5 Radenovic et al.

1

2

3

4

5

6
7

8

9

10

11

12

13

14

15

16

17

18

19

20

21

22

23

24

25

26

27

28

29

30

31

32

33

34

35

36

37

38

39

40

41

42

43

44

45

46

47

48

49

50

51

52

53

54

55

56

57

58

59

60

URL: http://mc.manuscriptcentral.com/tandf/tmph 


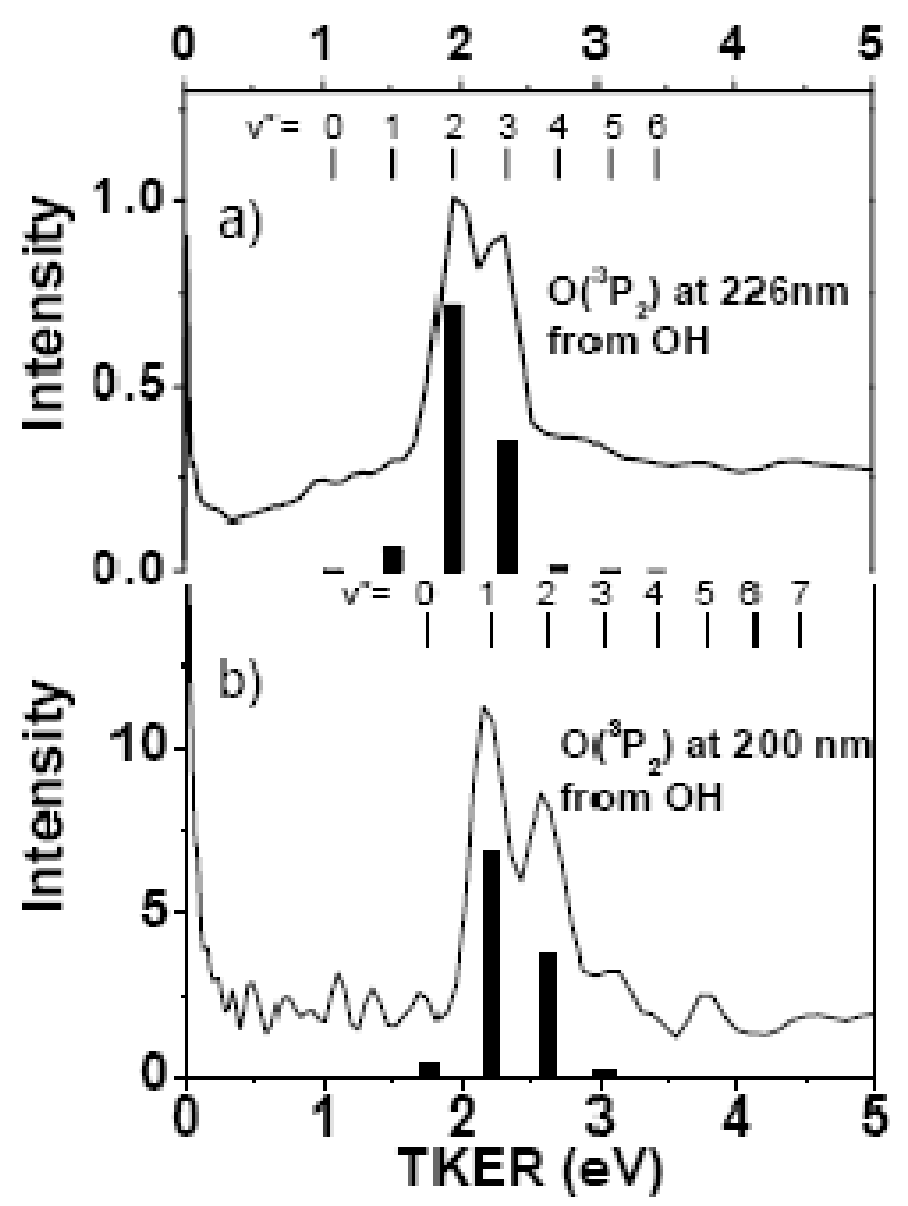

Figure 6. Radenovic et al. 


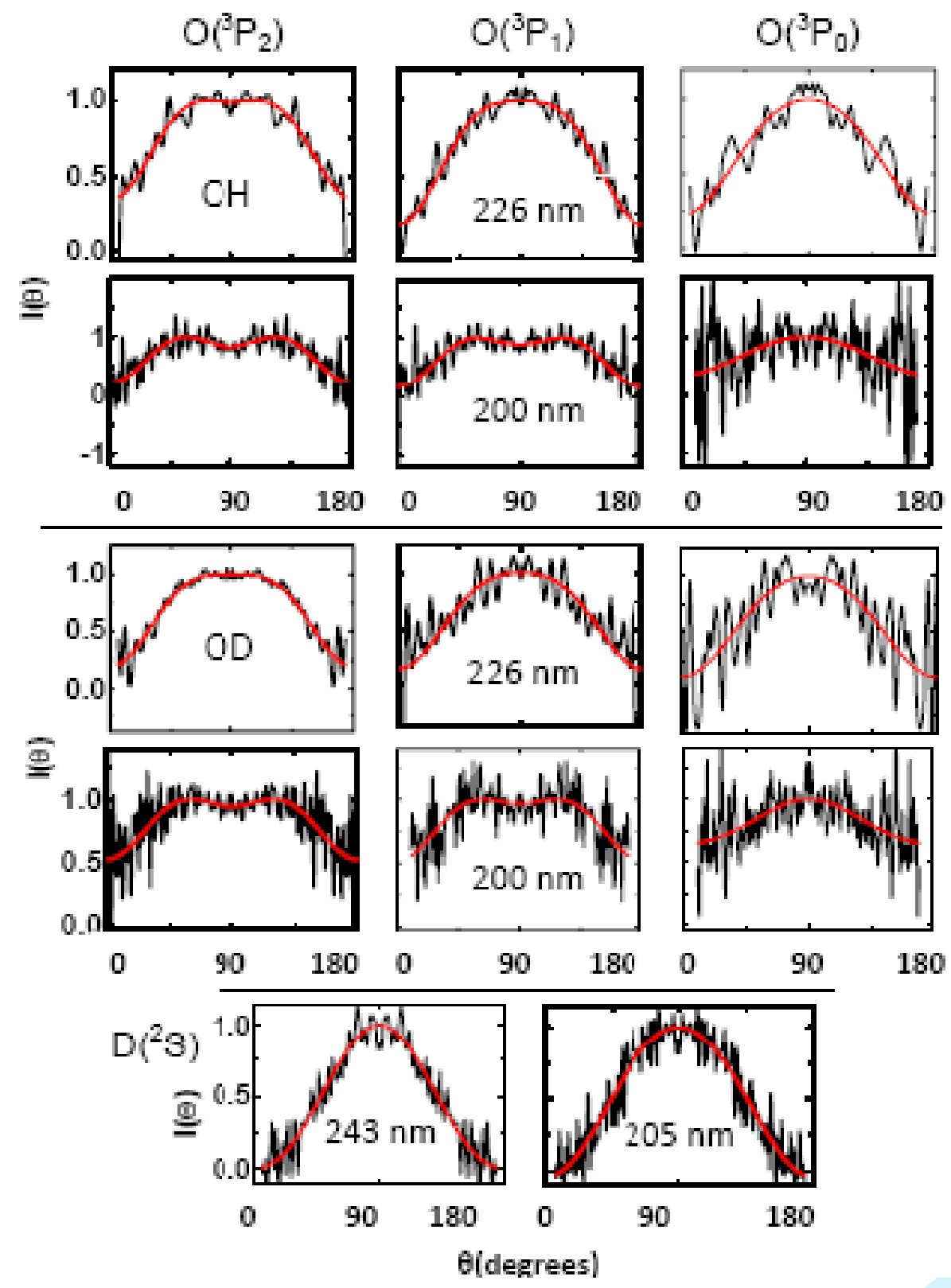

Figure 7. Radenovic et al.

URL: http://mc.manuscriptcentral.com/tandf/tmph 

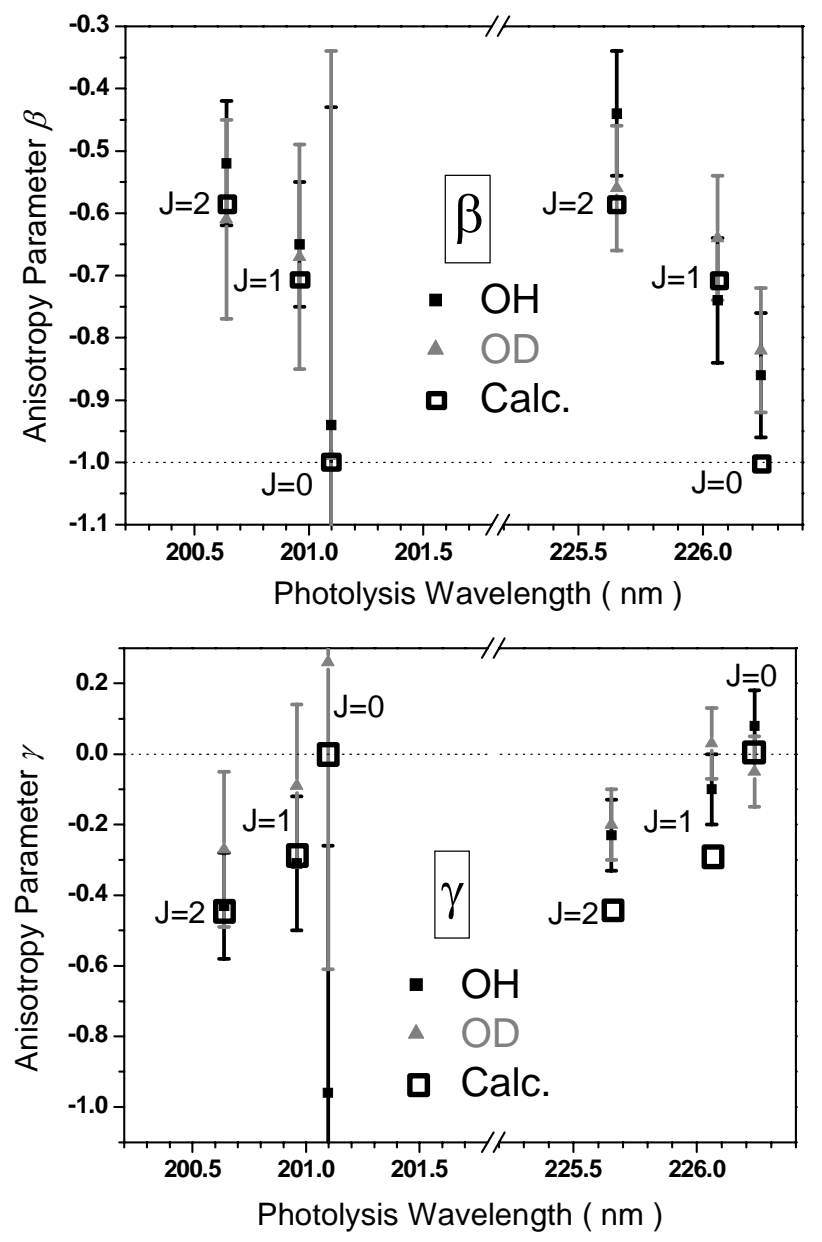

Figure 8. Radenovic et al. 


1
2
3
4
5
6
7
8
9
10
11
12
13
14
15
16
17
18
19
20
21
22
23
24
25
26
27
28
29
30
31
32
33
34
35
36
37
38
39
40
41
42
43
44
45
46
47
48
49
50
51
52
53
54
55
56
57
58
59
60

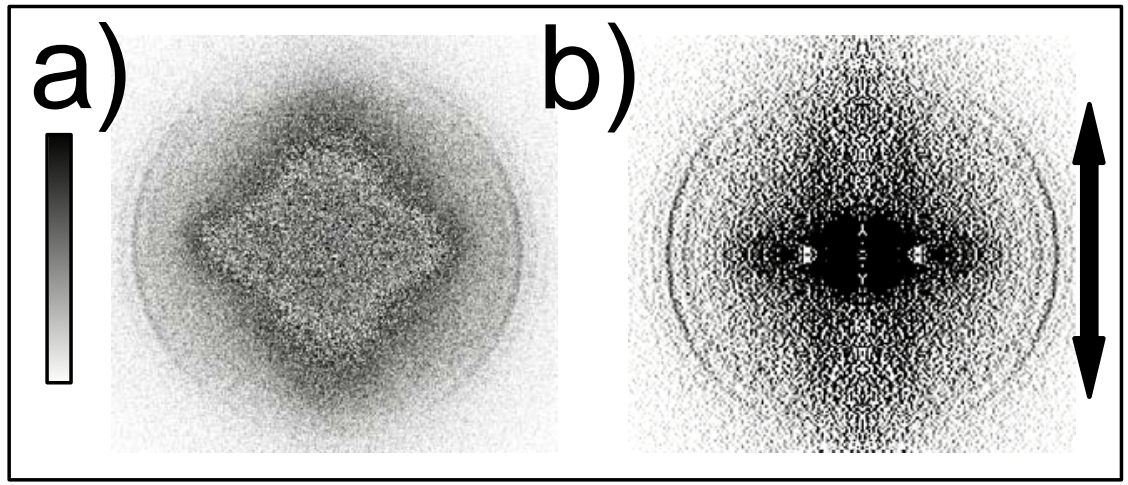

Figure 9. Radenovic et al. 


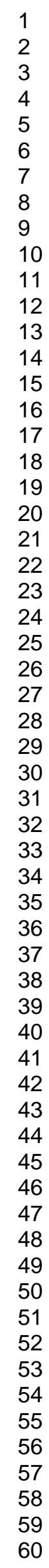

URL: http://mc.manuscriptcentral.com/tandf/tmph 


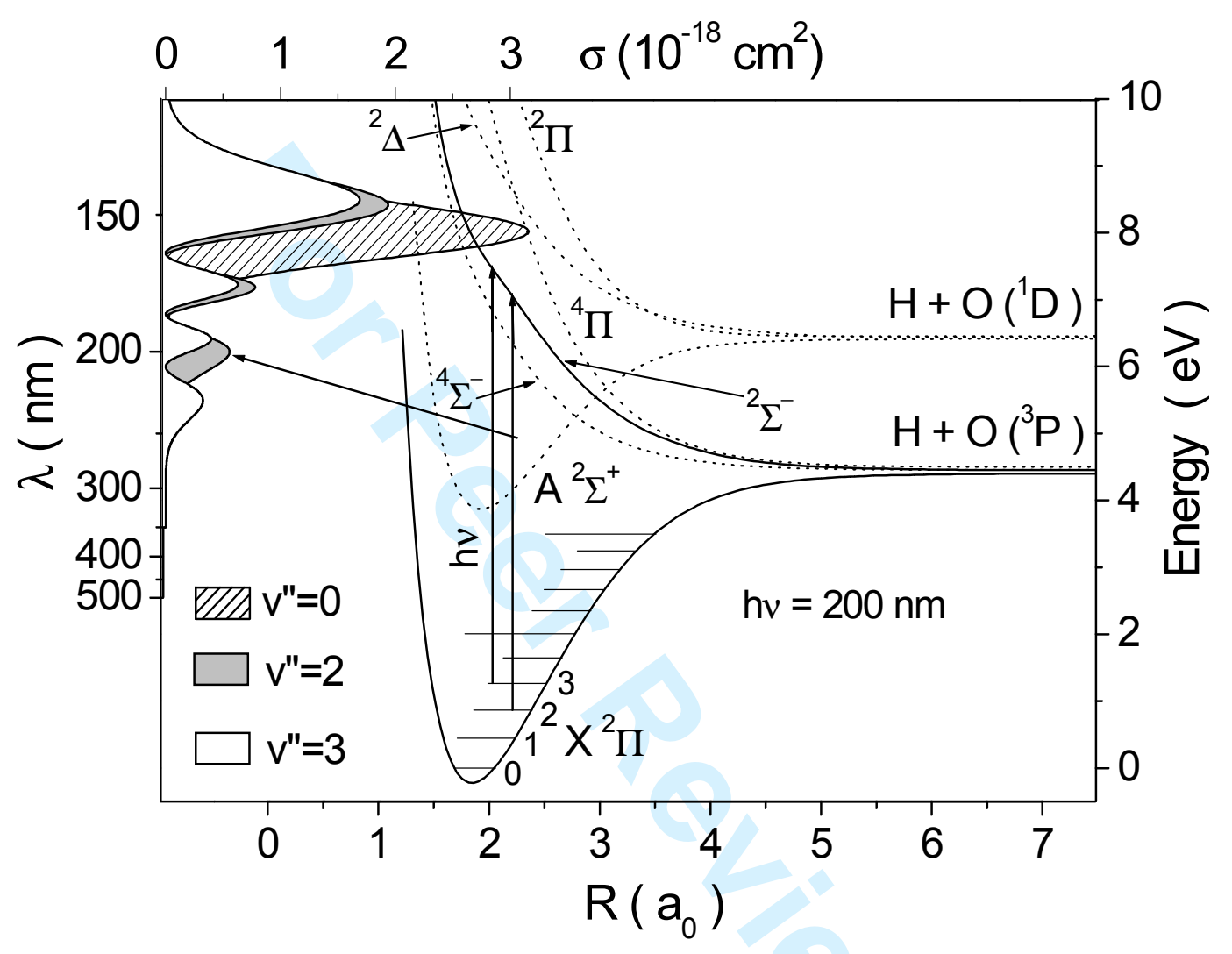

Figure 1 Radenovic et al. 


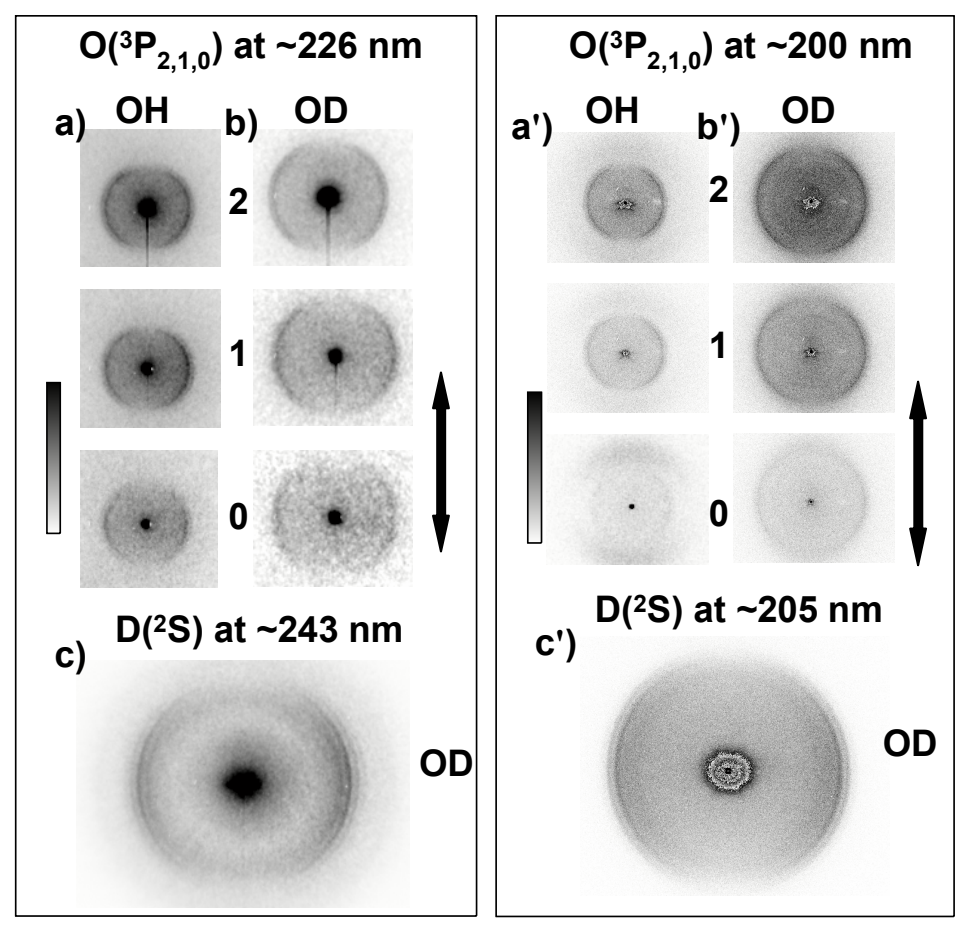

Fig. 2 Radenovic et al. 


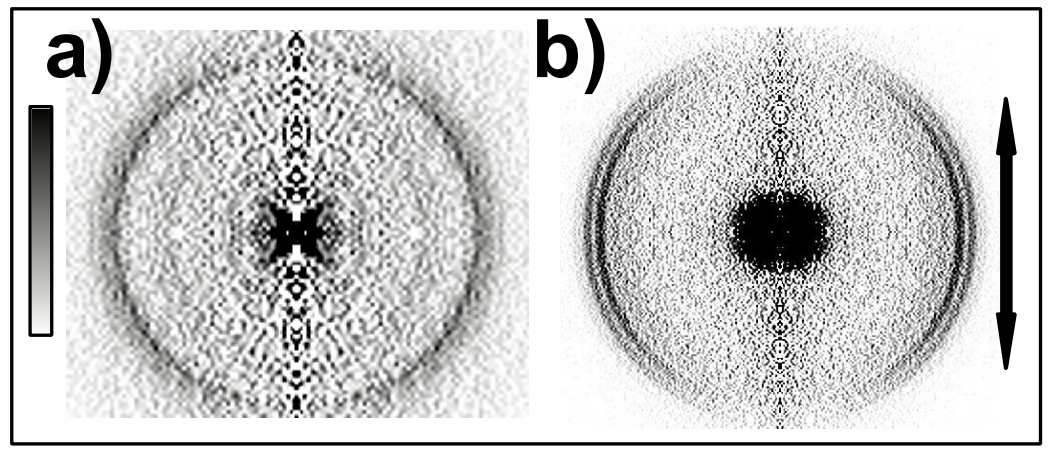

Figure 3 Radenovic et al. 


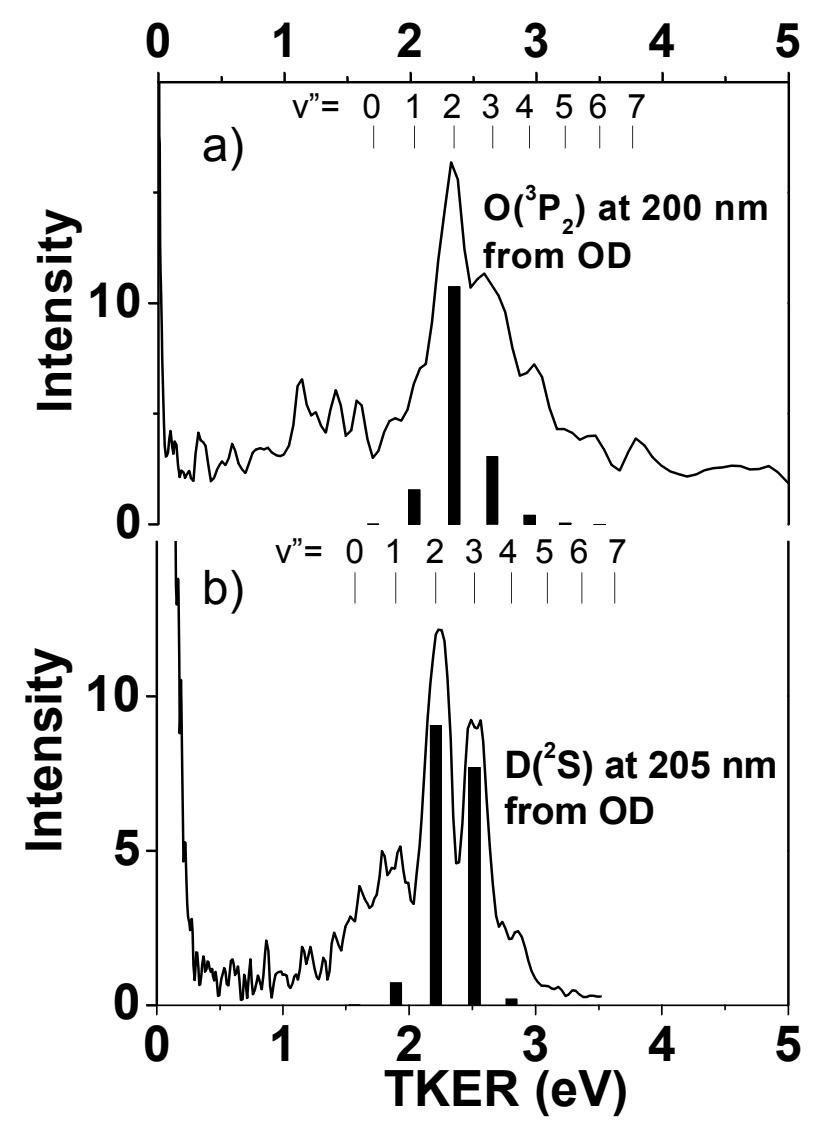

Figure 4. Radenovic et al. 


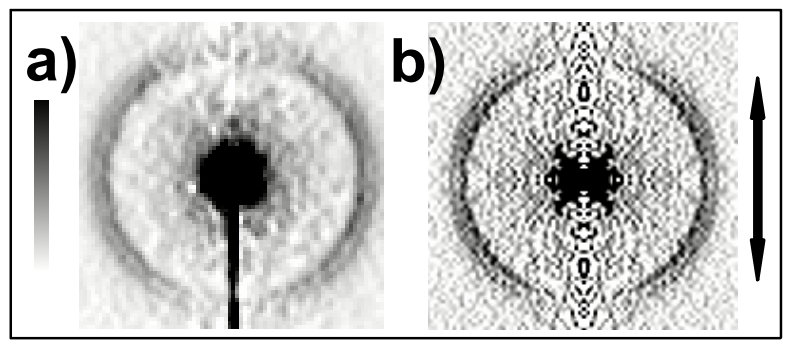

Figure 5 Radenovic et al. 


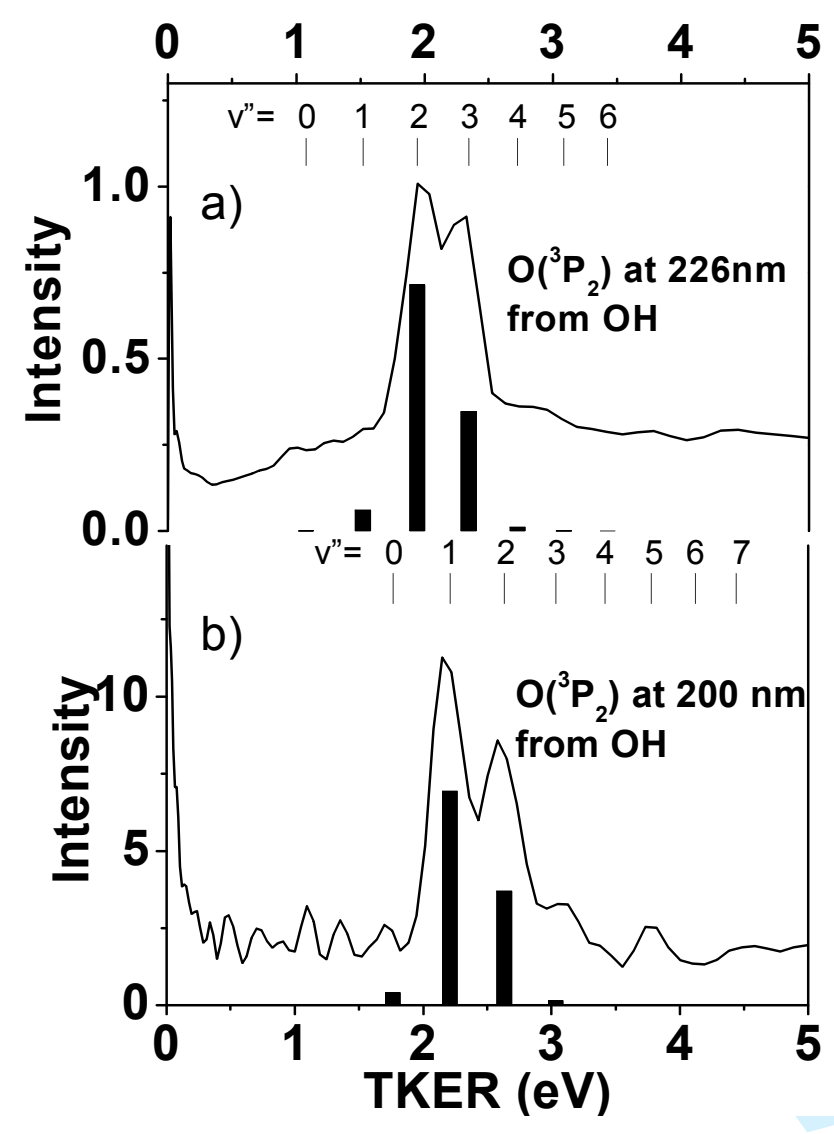

Figure 6. Radenovic et al. 
a)
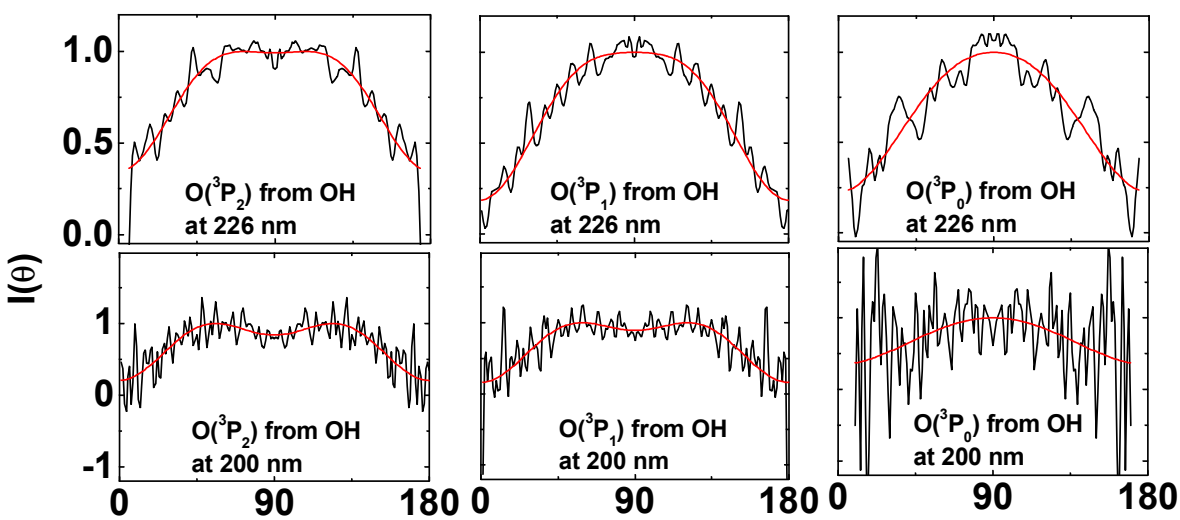

Angle $\theta$ [deg]

b)
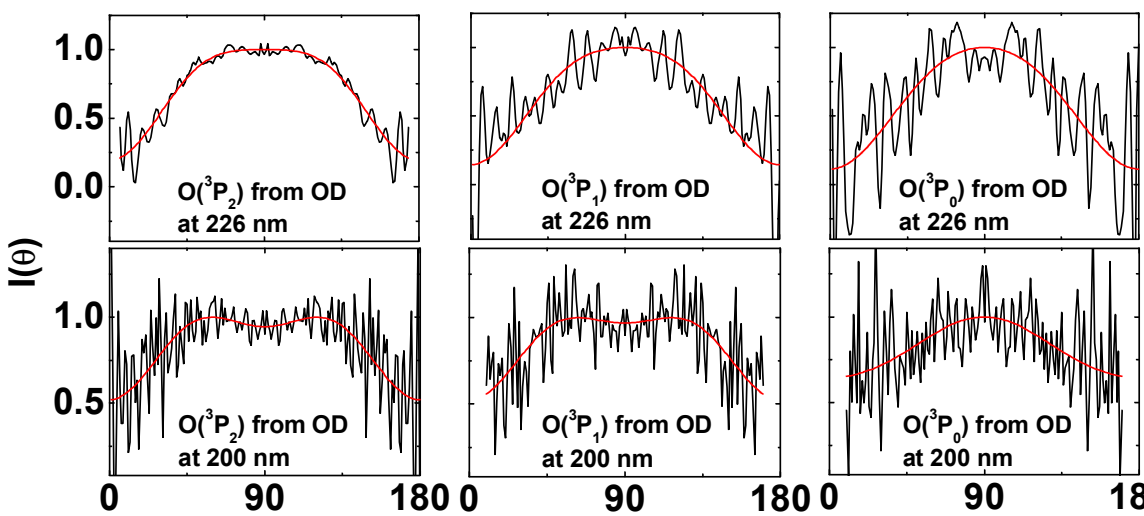
at $226 \mathrm{~nm}$
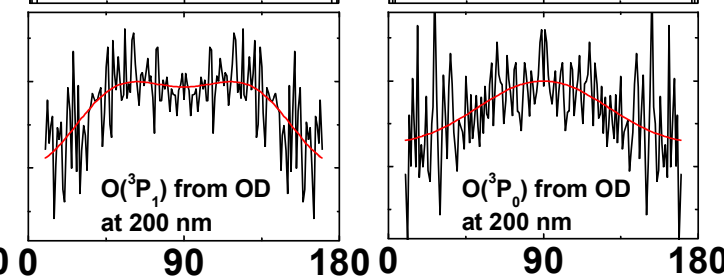

c)

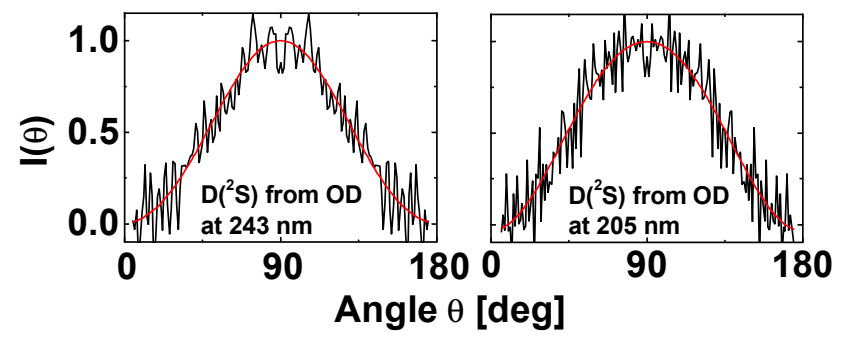

Figure 7. Radenovic et al. 

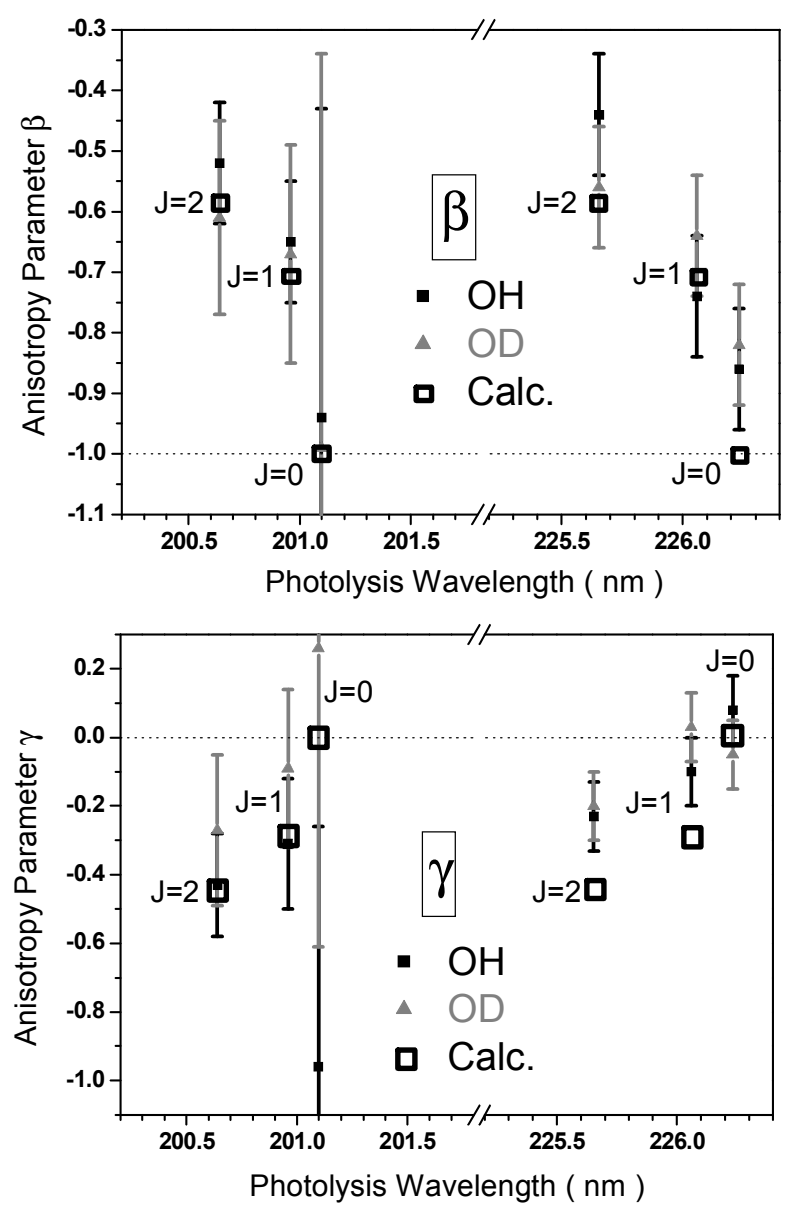

Figure 8. Radenovic et al. 


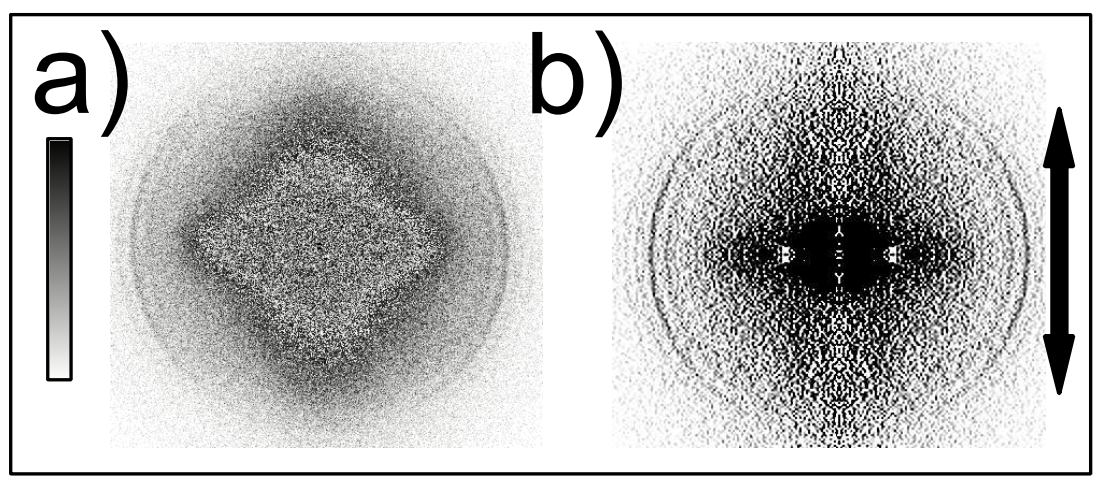

Figure 9. Radenovic et al. 